\title{
Accuracy of Implant Placement Utilizing Stereolithographic Guides Printed with and without Cross-arch Stabilization Struts
}

Caitlin Libby DDS

West Virginia University, clibby@mix.wvu.edu

Follow this and additional works at: https://researchrepository.wvu.edu/etd

Part of the Prosthodontics and Prosthodontology Commons

\section{Recommended Citation}

Libby, Caitlin DDS, "Accuracy of Implant Placement Utilizing Stereolithographic Guides Printed with and without Cross-arch Stabilization Struts" (2021). Graduate Theses, Dissertations, and Problem Reports. 8218.

https://researchrepository.wvu.edu/etd/8218

This Thesis is protected by copyright and/or related rights. It has been brought to you by the The Research Repository @ WVU with permission from the rights-holder(s). You are free to use this Thesis in any way that is permitted by the copyright and related rights legislation that applies to your use. For other uses you must obtain permission from the rights-holder(s) directly, unless additional rights are indicated by a Creative Commons license in the record and/ or on the work itself. This Thesis has been accepted for inclusion in WVU Graduate Theses, Dissertations, and Problem Reports collection by an authorized administrator of The Research Repository @ WVU. For more information, please contact researchrepository@mail.wvu.edu. 


\title{
Accuracy of Implant Placement Utilizing Stereolithographic Guides Printed with and without Cross-arch Stabilization Struts \\ Caitlin Libby, D.D.S.
}

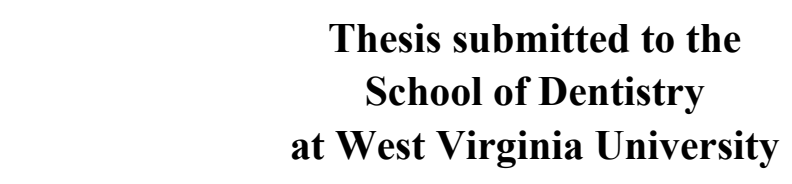

In partial fulfillment of the requirements for the degree of

Master of Science

In

Prosthodontics

\author{
Matthew Harper, D.D.S., M.S. (Chair) \\ Shelby Alexander, D.D.S., M.S., F.A.C.P. \\ Bryan Weaver, D.D.S, M.D. \\ Department of Restorative Dentistry
}

Morgantown, West Virginia

2021

Keywords: [accuracy, guided implant placement, stereolithographic surgical guide, stabilization strut]

Copyright 2021 Caitlin Libby 


\author{
ABSTRACT \\ Accuracy of Implant Placement Utilizing Stereolithographic Guides \\ Printed with and without Cross-arch Stabilization Struts \\ Caitlin Libby, D.D.S.
}

Objectives: The purpose of this study was to assess the accuracy of implant placement using stereolithographic guides printed with and without stabilization struts by comparing the postoperative position to the planned implant position.

Methods: A pre-operative cone-beam computed tomography (CBCT) of a drillable maxillary model was obtained and data was uploaded into coDiagnostiX for preoperative planning. The implant position was planned in an edentulous space of \#5 using a 3.3x10 Tapered (BLT) implant (Straumann). Ten surgical guides were designed utilizing a stabilization strut (Group A), while ten guides were designed without the stabilization strut (Group B). Twenty guides total, ten in each group, were 3-D printed and $5 \mathrm{~mm}$ sleeves were inserted to allow full preparation of the osteotomy. The osteotomy sites were prepared following Straumann guided surgery protocols, apart from utilizing irrigation. Twenty $3.3 \times 10 \mathrm{~mm}$ BLT implants were placed partially guided in the maxillary models. The implants were placed freehanded until full depth was achieved. Post-operative CBCT scans of each sample were obtained, uploaded into coDiagnostiX, and merged with the planned implant position. The treatment evaluation tool was used to compare the post-operative implant positions to the planned position. As the guides were printed in two separate batches, both of which containing equal numbers of Group A and Group B templates, the same evaluation tool was used to determine if there was any batch-to-batch 3-D print variability.

Results: No significant differences were found between the planned and post-operative implant position of implants placed using Group A guides and implants placed using Group B guides. There was a statistically significant difference found between the prints in Batch 1 and Batch 2, although it is important to note that the differences would not be clinically significant. The angle measurement is significantly greater in Print Batch $1(\mathrm{P}=.0115)$. The Vestibular (Base) measurement is significantly greater in Print Batch $1(\mathrm{P}=.0076)$, as is the 3D Offset (Apex) measurement $(\mathrm{P}=.0155)$. The Distal (Apex) measurement is weakly significantly $(90 \%$ confidence level) greater in Print Batch $1(\mathrm{P}=.0684)$, while the Vestibular (Apex) measurement is significantly greater in Print Batch $1(\mathrm{P}=.0061)$.

Conclusions: No significant differences were found in post-operative implant position of implants placed utilizing surgical guides with a stabilization strut (Group A) vs the guides without the stabilization strut (Group B). Further studies using larger samples sizes are indicated in order to validate if significant differences can be expected between guides printed and processed in difference batches. 


\section{ACKNOWLEDGEMENTS}

I sincerely would like to thank the following for their guidance, assistance, and contributions:

Dr. Matthew Harper - Thank you for your guidance, feedback, and support throughout this project as not only my committee chair, but also as a mentor, friend, and Prosth brother from day one. I am very grateful for your mentorship throughout this process.

Dr. Shelby Alexander and Dr. Bryan Weaver - Thank you for your insight and support as valued committee members. I am thankful for all that you've taught me in both dental school and in residency.

Dr. Matthew Bryington - Thank you for your ideas, feedback, and continued support throughout the entirety of this study.

Dr. Vivia Sequeira - Thank you for your constant support as my close friends and coresident over the past few years.

Dr. Greg McMahon - Thank you for going above and beyond. I am immensely thankful for your thorough assistance and contributions to the statistical analysis and data visualizations.

Lyndsey Gray - Thank you for your assistance in purchasing materials for this study. Eileen Bardwell- Thank you for your generous donation of Straumann materials. 


\section{TABLE OF CONTENTS}

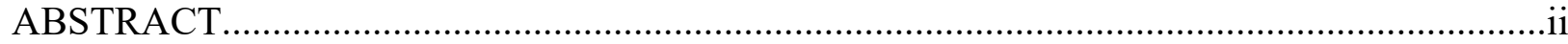

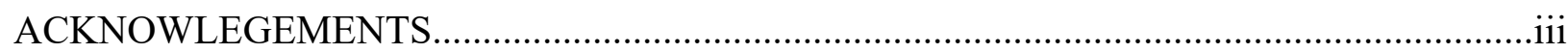

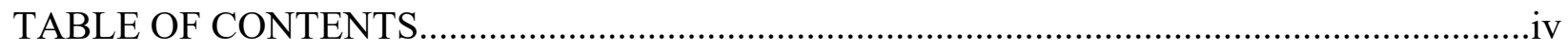

LIST OF TABLES.

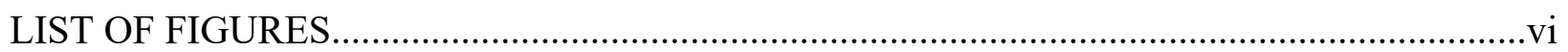

LIST OF ABBREVIATIONS.........................................................................................

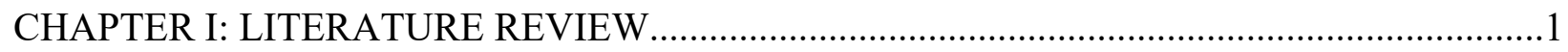

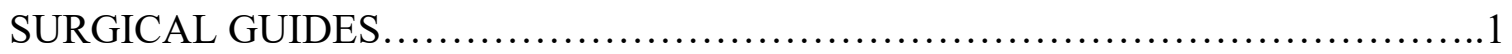

CBCT

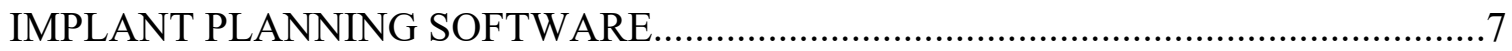

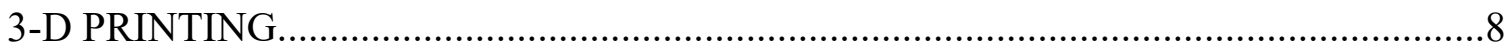

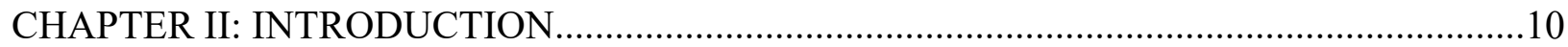

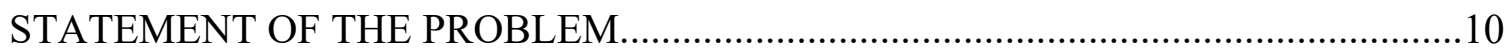

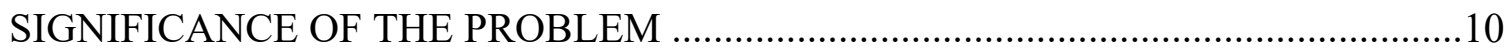

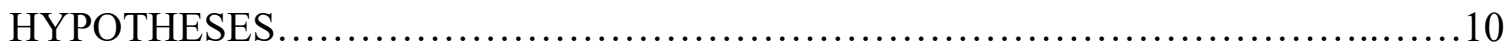

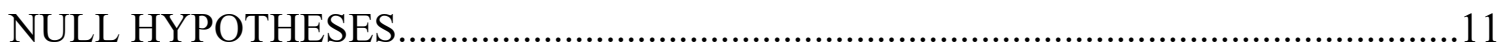

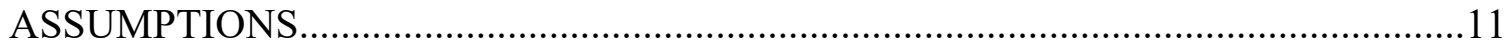

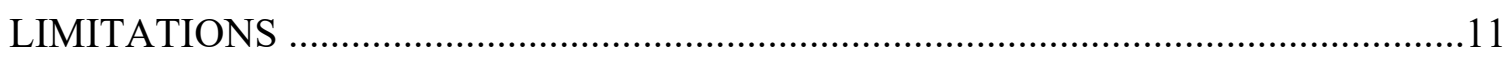

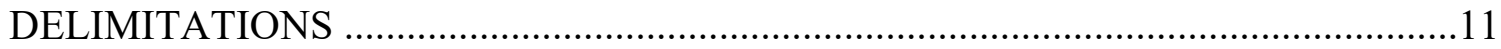

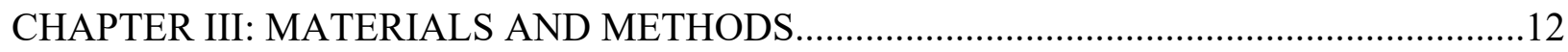

PREPARATION FOR IMPLANT PLANNING ...................................... 12

FABRICATION OF SURGICAL GUIDES .......................................13

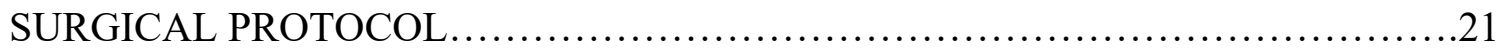

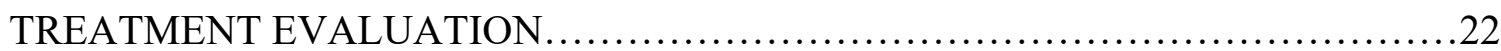

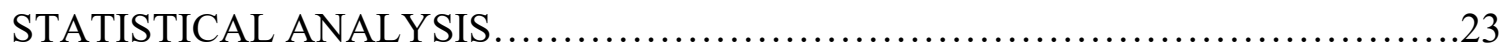

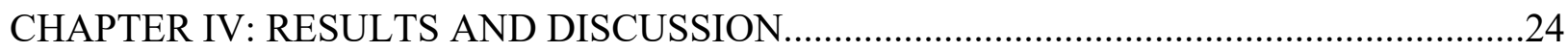

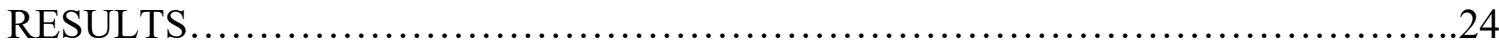

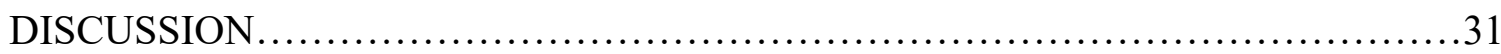

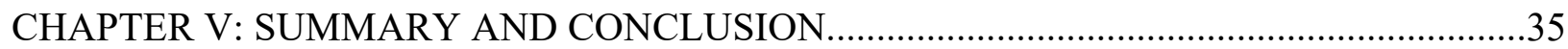

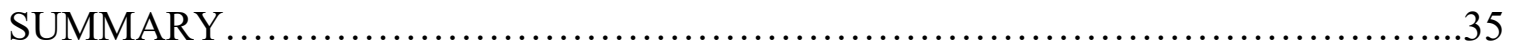

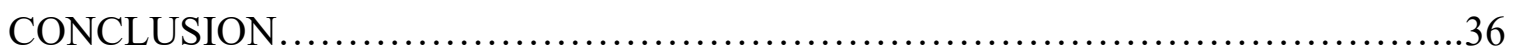

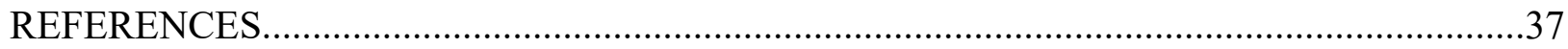

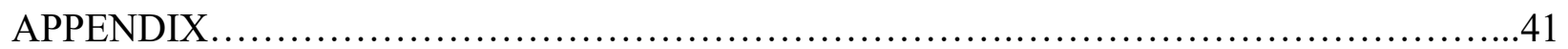




\section{LIST OF TABLES}

Table 1: Difference measurements obtained from the treatment evaluation software for Group A and Group B samples.

Table 2: Summary of means, standard deviations and p-values from 2-way tests comparing means of deviations (trueness) for all variables by group. ${ }^{*}$ denotes results from non-parametric Wilcoxan test. All other results are from the parametric Student t-test.

Table 3: Summary means, standard deviations and of p-values from 2-way ANOVA and Tukey HSD tests comparing means of deviations (trueness) for all measurement variables by print batch.

Table 4: Summary of means and standard deviations (SD) of measurements and p-values from 2way ANOVA and Tukey HSD tests comparing means of deviations (trueness) for all measurement variables by print batch. 


\section{LIST OF FIGURES}

Figure 1: (A) Partially edentulous maxillary model used that correlates to Type II bone density per manufacturer (ACT/Paradigm, Escondido, CA); (B) Segmented DICOM file of initial CBCT scan uploaded into coDiagnostiX

Figure 2: Alignment of Sagittal, Coronal, and Axial Planes

Figure 3: Path of insertion selected for the surgical guide

Figure 4: Group A surgical guides were designed to be supported by teeth \#2-4, \#6-\#7, \#9-\#11. Tooth \#12 was selected and positioned across the arch to be placed on posterior tooth \#3 for incorporation of the cross-arch stabilization strut. An additional edentulous space in area of \#8 is also present on the study model. This was not selected in order for the guide to remain solely tooth-supported.

Figure 5: Visualization of the inspection windows of Group A surgical guides.

Figure 6: Elimination of the cross-arch stabilization strut in the design of Group B surgical guides.

Figure 7: Visualization of inspection windows of Group B surgical guides

Figure 8: Side by side comparison of Group A and Group B surgical guide design

Figure 9: Angulation on build platform and location of the supports.

Figure 10: Layout of Batch 1 prints including five guides in Group A and five guides in Group B (ten guides total). This Preform layout was saved and used to print Batch 2 prints so that the angulation and layout between batches remained the same.

Figure 11: Finished prints remaining on build platform.

Figure 12: Build Platform after removal from Formlabs2 3D printer

Figure 13: Cured in the FormLabs Form Cure Oven $60^{\circ} \mathrm{C}$ for 30 minutes as recommended for Dental SG Resin.

Figure 14: Evaluation of intaglio surface of Group A and Group B surgical guides

Figure 15: Group A guide assigned to corresponding model

Figure 16: Group B guide assigned to corresponding model

Figure 17: (A) Osteotomy created using the $2.2 \mathrm{~mm}$ pilot drill at $800 \mathrm{RPM},(\mathrm{B})$ Enlargement of the same osteotomy site using the $2.8 \mathrm{~mm}$ pilot drill at $600 \mathrm{RPM}$

Figure 18: Comparison of means of deviation (trueness) by group for all variables.

Figure 19: Comparison of means of deviation (trueness) by print batch for all variables.

Figure 20: Comparison of precision of implants between the two groups for all measurements. 


\section{LIST OF ABBREVIATIONS}

$\mathrm{CBCT}=$ Cone-beam Computed Tomography

BLT $=$ Bone Level Tapered

$\mathrm{SG}=$ Surgical Guide

3-D = Three Dimensional

2-D = Two Dimensional

ANOVA $=$ Analysis of varience

MSCT $=$ Multi-slice computed tomography

$\mathrm{CBCT}=$ Cone beam computed tomography

TFT $=$ Thin-film transistor

FDK method $=$ Feldkamp method

$\mathrm{FOV}=$ Field of view

ALARA/ALADA $=$ As low as reasonably/diagnostically acceptable

TLD $=$ Thermoluminescent dosimeter

$\mathrm{MTF}=$ Modulation transfer function

$\mathrm{CAI}=$ Computer-aided implantology

DICOM $=$ Digital Imaging and Communications in Medicine

STL $=$ Standard Tesselation Language

$\mathrm{SLA}=$ Stereolithography

IPA = Isopropyl alcohol

$\mathrm{CAD} / \mathrm{CAM}=$ Computer aided design/computer aided manufacturing $3 \mathrm{DP}=3-\mathrm{D}$ printing 


\section{Chapter I: Literature Review}

\section{Surgical Guides}

A successful treatment outcome in regard to implant therapy requires prosthetically driven 3-D positioning. ${ }^{1 ; 2}$ Hard and soft-tissue defects are the most prominent pathological clinical findings associated with dental implants that can usually be avoided by proper preoperative planning. Intraalveolar, dehiscence, fenestration, horizontal ridge defects, and vertical ridge defects are all examples of hard-tissues defects at implant sites, while soft-tissue defects predominantly include deficiencies in quality and volume with a lack of keratinized tissue. Complications such as marginal bone loss, soft-tissue inflammation, and soft-tissue recession may result from these deficiencies. Improper implant positioning is one of the etiologies for tissue defects that can be prevented with careful preparation and precise implant placement in the prosthetically optimal location. Thus, prosthetically driven planning of the implant position is vital for a successful post-operative outcome, supporting the use of surgical guides. $2 ; 4$

In the literature, there is significant debate about which form of surgical guide is the most accurate: bone-supported, tooth-supported, or mucosa-supported. Other variables for guided surgery, such as flap or flapless surgical approach, location (maxillary or mandibular arch), stabilization techniques such as fixation pins, and performing partially or fully guided implant placement, are somewhat more consistent. ${ }^{3 ;}$ 9; 10;11;12;13;14 According to the literature, a flapless approach is considered more accurate compared to a flapped approach. ${ }^{11}$ The use of a flapless approach during the surgical procedure typically results in smaller angular deviations, shorter surgery duration, less invasive procedures, improved gingival esthetics, and overall improved implant placement accuracy. ${ }^{11,15}$ Unfortunately, when assessing positioning in the maxillary or mandibular arch, as well as comparing partially versus fully guided implant placement, there is less consistent information. Furthermore, regardless of the surgical guide type, the use of fixation screws significantly improved angular accuracy. ${ }^{11 ; 14}$

The three main types of SLA generate surgical guides include bone-supported, toothsupported, and mucosa-supported. In 2018, a systematic review and meta-analysis that included 
34 articles assessed which type of guide was considered the most accurate of the three. However, a consensus could not be reached amongst the divided conclusions, with half of the articles saying that mucosa-supported guides were more reliable and the other half claiming that toothsupported guides were the most accurate. ${ }^{17}$

Turbush et al conducted an in vitro study that utilized acrylic mandibles to assess the accuracy implant placement using the three types of surgical guides. ${ }^{15}$ Deviations at the apex and implant platform were found to be substantially different. The tooth-supported guide was found to be more accurate at the apex, while both the tooth-supported and bone-supported guides were more accurate at the implant platform compared to the mucosa-supported guide. As a result, they came to the conclusion that the tooth-supported surgical guide was the most accurate of the three. ${ }^{15}$

Ozan et al also evaluated all three surgical guide types and compared their accuracy. ${ }^{16}$ This in vivo study also found that the tooth-supported guides were significantly more accurate at the implant's apex compared to guides supported by bone or mucosa. They also found that the bone-supported guide yielded greater angular deviations than the tooth-supported guide. ${ }^{16}$ The in vitro study by Turbush et al revealed that the bone-supported guide was significantly more accurate than the mucosa-supported guide, in contrast to the in vivo study by Ozan et al which found that the mucosa-supported guide yielded slightly better results than the bone-supported guide. Both of these studies, however, agreed that the accuracy of tooth-supported surgical guides was superior. ${ }^{15,16}$

Although the literature seems to accept that fully guided results are generally superior to partially guided results, there is disagreement on whether the difference is clinically important. Kuhl et al used stereolithographic (SLA) guides to place 38 implants in cadaver mandibles to compare the difference between partially guided and fully guided implant placement. ${ }^{10}$ There was a trend toward improved precision with completely guided positioning, however statistically significant differences were not found. ${ }^{10}$ In contrast to partially guided implant placements, a meta-analysis found that fully guided implant placements resulted in significantly better implant angulation and reduced apical error. ${ }^{11}$

The level of implant placement accuracy one can expect when using a stereolithographic surgical guide has been discussed numerous times in literature. Countless studies have 
provided statistical analyses on guided implant placement accuracy. These results also vary between clinical and in vitro studies. Attempting to put the information into context for the various study types can be difficult. Differences in accuracy of implant placement with use of a surgical guide between in vitro and in vivo studies is a topic that warrants discussion.

When discussing implant placement accuracy, the term trueness refers to the closeness between the arithmetic mean of a large sample of test results and the value of the true or accepted reference, whereas the term precision describes the degree of distribution of actual values. A higher degree of precision exists when actual values are close to each other. ${ }^{2 ; 18}$ An in vitro study by Guentsch et al investigated the accuracy of various implant placement protocols in terms of trueness and precision. ${ }^{2}$ Implants were placed in models utilizing different techniques including partially-guided, free-handed, and fully guided; with varying sleeve heights of $2 \mathrm{~mm}, 4 \mathrm{~mm}$, and $6 \mathrm{~mm}$ in the fully guided groups. Implant placement with static surgical guides produced reproducible (high precision) and predictable (high trueness) results, whereas free-handed placement results were less predictable and reproducible. The averages for their results in the partially guided group were 1.75 degrees in angle deviation, $0.18 \mathrm{~mm} 3-\mathrm{D}$ offset at the base, $0.19 \mathrm{~mm}$ offset at the base, $0.18 \mathrm{~mm}$ buccal deviation at the base, and $0.24 \mathrm{~mm}$ apical deviation at the base. Their averages at the apex for the same partially guided group included a mean 3D offset of $0.43 \mathrm{~mm}$, distal discrepancy of $0.49 \mathrm{~mm}$, buccal deviation of $0.41 \mathrm{~mm}$, and an apical deviation of $0.24 \mathrm{~mm}$ at the apex. ${ }^{2}$

A prevalent cause of complication in implant therapy includes infection by means of contamination of the open wound during the surgical placement of implants. ${ }^{5}$ For this reason, thorough sterilization of dental instruments is vital. There are three categories of acceptable methods of disinfection and sterilization into which medical and dental instruments are divided. These categories include critical, semi-critical, and non-critical, and depend on the possible risk for infection transmission. Templates for implant drill guides are semi-critical and require either high level disinfection or heat sterilization. ${ }^{6}$

Microbial contamination of drill guide templates can occur throughout the process of fabrication, rendering proper sterilization of the guides imperative prior to their use in implant placement. ${ }^{6 ; 7}$ The most widely used sterilization method in dental offices is steam sterilization utilizing an autoclave. This method involves sterilizing items in an enclosed, pressurized space 
using saturated steam. Most autoclaves in the dental setting possess two common settings: a normal cycle (at a pressure of +1 bar and temperature of $121^{\circ} \mathrm{C}$ for 20 minutes) and a fast cycle (at a pressure of +2 bar and temperature of $134{ }^{\circ} \mathrm{C}$ for 10 minutes). ${ }^{7}$ The effect of these sterilization methods on the dimensional changes and mechanical properties of the 3-D printed surgical guides is a topic that warrants discussion.

A pilot study by Török et al investigated the effects of disinfection and three different sterilization methods on the mechanical properties and dimensional changes of 3-D printed guides. $^{7}$ The tested sterilization methods included plasma sterilization, autoclave sterilization $\left(+1\right.$ bar) at $121{ }^{\circ} \mathrm{C}$ for 20 minutes, and autoclave sterilization $\left(+2\right.$ bar) at $134{ }^{\circ} \mathrm{C}$ for 10 minutes. They found no measurable deformation or structural change in the sterilized guides despite the high temperature in the autoclave, with the exception of the hardness of the $134{ }^{\circ} \mathrm{C}$ sterilized guides. There was a statistically significant difference in hardness strength in steam sterilization at $134{ }^{\circ} \mathrm{C}$, while hardness of the material was unchanged by plasma sterilization and steam sterilization at $121^{\circ} \mathrm{C}$. No significant changes were found in the flexural or compressive strength in the material in all methods. The findings indicated that sterilizing 3-D printed guides at both low and high temperatures is effective since the tested surgical guides were not significantly deformed or damaged by high temperature steam sterilization. They concluded that plasma sterilization and autoclave steam sterilization at $121^{\circ} \mathrm{C}$ are both effective methods for sterilizing 3-D printed surgical guides. The autoclave remains the recommended choice for dental offices due to the large size and high cost of plasma sterilizers. ${ }^{7}$

When choosing the most appropriate method of sterilization, it is also important to keep in mind the manufacturer's recommendations of the resin type used to fabricate the 3-D printed surgical guide. For the current study, clear UV-cured methacrylate photopolymerizing resin material (Dental SG; Formlabs Inc.) was used. The approved cycles for sterilization of Dental SG printed guides includes autoclave treatments of $121^{\circ} \mathrm{C}$ for 15 minutes, $134^{\circ} \mathrm{C}$ for 6 minutes, and $138^{\circ} \mathrm{C}$ for 3 minutes, with or without the use of sterilization pouches. ${ }^{8}$ For the current study, the guides were autoclaved with use of sterilization pouches at $121^{\circ} \mathrm{C}$ for 15 minutes as indicated for patient use. 


\section{Cone Beam Computed Tomography (CBCT)}

Obtaining the appropriate radiograph is necessary in implant planning. Two-dimensional options include the periapical and panoramic radiographs. Periapical radiographs possess high spatial resolution and can be used to diagnose pathology on adjacent dentition and evaluate the bone height of the edentulous space, but they can overlap anatomic structures and are not adequate for implant planning. Panoramic radiographs are more useful for diagnostic purposes. They can be used for evaluation of bone height, viewing the maxillary sinuses, and determining the location of the inferior alveolar nerve, and aid in preliminary treatment planning for potential placement of dental implants. ${ }^{19 ; 20}$ Panoramic radiographs have limited resolution, possess approximately $25 \%$ distortion, and are not the ideal choice for implant planning due to the limitations of 2-D imaging. ${ }^{20 ; 21 ; 22}$

The inadequacy of two-dimensional radiographic images have led to their elimination in the use of implant planning since the introduction of three-dimensional imaging technology. ${ }^{9}$ Potential 3-D images used in dentistry include conventional computed tomography (CT), multislice computed tomography (MSCT), and CBCT. Conventional CTs are digital images created by combining multiple exposures of a fan-shaped x-ray beam passing through a tissue slice at various angles. Conventional CTs have been shown to produce image accuracy comparable to CBCTs and MSCTs, but at a higher cost, with longer acquisition times, higher radiation doses, and lower technique sensitivity. ${ }^{11 ; 23 ; 24 ; 25}$ Multi-slice CTs use multiple detector rows (up to 320) in a 2-D array as an alternative to conventional CTs' one-dimensional detector arcs, although this necessitates a large number of rotations. ${ }^{20}$

CBCTs were specifically designed for the maxillofacial region as a replacement for conventional CTs. Utilizing a cone-shaped source of ionizing radiation, CBCTs capture the data set more efficiently with a less exclusive detector.. ${ }^{23}$ CBCTs allow alteration of the field of view and use reduced voxels, resulting in higher spatial resolution. ${ }^{23 ; 26}$ However, they have been shown to possess a lower contrast resolution compared to conventional CTs. ${ }^{20}$

CBCTs are currently the most common method of obtaining 3-D images for implant planning. ${ }^{24 ; 25}$ An x-ray source emits a cone-shaped beam onto a detector which spins around the region of interest. This process captures numerous sequential planar projection images. ${ }^{25}$ The flat-panel detectors are comprised of a photo diode array and a large-area pixel arrangement of 
hydrogenated amorphous silicon thin-film transistors (TFTs). A scintillator detects the x-rays indirectly, converting the information into visible light that is recorded in the photo diode array. This signal information is carried by the TFTs. The rays are typically pulsed to correspond with detector sampling. This action can reduce exposure time and thus the dose of radiation. The multiple 2-D images captured are often known as raw, basis, or frame images, and bear a resemblance to that of a lateral cephalometric radiograph. ${ }^{24 ; 25}$ These images comprise the total projection data.

Through a process known as reconstruction, the data is converted into a viewable format. This conversion utilizes a mathematical algorithm known as the Feldkamp (FDK) method. More projection data results in higher contrast and spatial resolution, as well as a greater signal-tonoise ratio, which results in reduction of metallic artifacts and a clearer image. ${ }^{22}$

One must understand the precision of the resulting images in order to use a CBCT as a problem-solving tool for implant planning. A study by Widmann et al discovered a mean error of $0.36 \mathrm{~mm} .{ }^{27}$ Another study compared authentic caliper measurements of a cadaver skull to digital measurements from four different CBCTs to determine device-specific errors. The actual and digital measurements differed significantly, with the digital exhibiting a slight overestimation. ${ }^{28}$ The modulation transfer function (MTF), volume voxel size, and gray value algorithm between the voxels can reduce the detail accuracy of a CBCT by approximately 0.100 $-0.150 \mathrm{~mm} .{ }^{29}$ After transferring the data set to a software viewer, a $0.5 \mathrm{~mm}$ difference between those devices can be expected. ${ }^{29}$

When selecting settings for CBCT scans, the ADA Council on Scientific Affairs recommends that dose optimization be followed. ${ }^{30}$ The dose of radiation of CBCT imaging varies depending on the unit used, FOV, voxel size, milliamp setting, sensor sensitivity, continuous vs pulsed scan type, and number of captured images. Clinicians should strive to reduce radiation dose by selecting the appropriate FOV, shortening scan times, and lowering the milliamp setting. ${ }^{30 ; 31}$ Care should be taken to reduce the risk to the patient while maintaining the diagnostic value of the scan. The acronym ALARA has been adopted to remind clinicians that every reasonable effort should be made to keep the patient exposure to ionizing radiation "As Low As Reasonably Achievable."25 


\section{Implant Planning Software}

The ultimate goal of guided implant placement is to adequately position the dental implant in the bone to provide the best function of the restored implant crown without esthetic or surgical compromises. ${ }^{9}$ Computer-aided implantology (CAI) software programs aid in the use and interpretation of CBCT Digital Imaging and Communications in Medicine (DICOM) files to plan the position of the implant while viewing the anatomy in cross-sectional images. ${ }^{29 ; 32 ; 33}$ Stereolithographic surgical guides can then be designed and 3-D printed to convey the planned position clinically during the surgical procedure. .,34 $^{9,34}$

The first step in implant planning is to upload the DICOM file into the software, then the scan can be oriented in sagittal, axial, and coronal planes. Oblique slices in the cross-sectional views can result if the arch is not positioned correctly. To prevent this distortion in the image, the sagittal plane must be used to align the Curve of Spee with the horizontal plane. The midline should then be centered in the axial plane while paying special attention to the arch form symmetry. Then, the occlusal plane is leveled in the coronal view.

To remove the scatter caused by amalgam and metallic restorations, the 3-D volume rendering requires segmentation. ${ }^{9 ; 34}$ The first step is to adjust the bone pixel or gray value thresholds in order to separate soft tissue from bone. $9 ; 29$ Removing the artifacts is a more timeconsuming process that necessitates the use of layers or removal tools to outline the tooth forms. ${ }^{9}$ The file is superimposed onto the model scan of the patient's dentition. This is done by selecting reference points that correspond on each image until an accurate alignment is achieved. ${ }^{19}$ If the scatter is not effectively removed during segmentation, the surface alignment may have a 0.45 mm discrepancy. ${ }^{29}$ If the implant is being planned on the mandibular arch, the inferior alveolar nerve can be traced after the imported Standard Tesselation Language (STL) file is aligned with the CBCT. When the software recognizes the nerve, it can alert the clinician when the planned implant position is within $2 \mathrm{~mm}$ of the outlined canal. ${ }^{9}$ This step, however, was not completed in this study as all implants were planned on a maxillary model. The software includes a library of implants to choose from. At this point, the planning of the implant position can begin. 


\section{D Printing}

Ongoing advancements in high quality desktop 3-D stereolithographic printers have prompted the in-office production of stereolithographic surgical guides at a reduced cost. The five categories of 3-D printing that are applicable in dentistry include extrusion printing, inkjet printing, laser melting/sintering, 3-D printing (3DP), and stereolithography (SLA) printing. ${ }^{35 ; 36}$ Extrusion printing involves the controlled dispensing of material through a nozzle as a three-axis stage moves according to computer programming. ${ }^{35}$ A three-axis stage is used in inkjet printing as well, but the content is dispensed in micrometer-sized drops. ${ }^{35}$ Another additive technique is laser melting, which involves manipulating a powder on a printing platform with a hightemperature laser light. As the platform goes up or down, the template is printed layer by layer. ${ }^{35}$ The only subtractive technique addressed is 3DP, in which material is extracted by water jetting while the object is repositioned. ${ }^{36}$ Stereolithography is the most common printing method used in the dentistry. ${ }^{37}$ In this process, a photosensitive resin bath is placed between a build platform and a polymerizing light source of a specific wavelength. The build platform descends into the resin bath, and the device directs light to polymerize the resin layer by layer, resulting in the planned 3-D object. $35 ; 36 ; 37$

A case study was conducted to assess the final error attributed to the printed stereolithographic guide. ${ }^{27}$ By superimposing an STL of the printed and planned guide, the maximum deviation was found to be $0.1 \mathrm{~mm} \cdot{ }^{27}$ Implants placed with an SLA printed guide can have an average angulation error of 5 degrees and a deviation of 0.9-1.0 mm. ${ }^{8 ; 1 ; 38 ; 39}$ This degree of precision greatly exceeds that of free-hand techniques, which display an average deviation of 2.0 to $2.5 \mathrm{~mm}^{8 ; 11 ; 38 ; 39}$

Stereolithography is part of the vat photopolymerization family of additive manufacturing technologies. ${ }^{40}$ All of these devices operate based on the same principle: a light source in the form of a laser or projector is used to cure the liquid resin into a hard plastic. Short molecular chains join together when SLA resins are exposed to specific wavelengths of light, polymerizing monomers and oligomers into solidified rigid or flexible geometries. ${ }^{40}$ The laser traces each layer on the surface of the liquid resin, after which a build platform descends and another layer of resin is wiped over the surface. This process is repeated until the print is complete. ${ }^{41}$ The most 
common use of SLA models in dental practice is to fabricate surgical drilling templates during the insertion of dental implants. ${ }^{42}$

The workflow for fabrication of SLA 3-D printed surgical templates starts with a welldesigned guide, which is then exported in a $3-\mathrm{D}$ printable file format (STL). ${ }^{40} \mathrm{~A}$ software included with the printer allows specification of printing settings, alteration of template angulation and layout on the build platform, and slice the digital model into layers for printing. This software then sends the instructions to the printer via a cable or wireless connection and printing can begin. Most printers include a cartridge system for automatic refill of the resin, allowing the machine to run unattended. ${ }^{40}$

After printing, parts must be rinsed in isopropyl alcohol (IPA) to remove any uncured resin from their surfaces. After the parts have been rinsed and dried, most materials require postcuring. The post-curing process allows the parts to reach their maximum strength and stability. ${ }^{40}$ The last steps involve removing the supports from the cured template, sanding or finish the remaining support marks with the appropriate cur for a smooth finish, and insertion of the guide sleeve. 


\section{Chapter 2: Introduction}

The deviation between the planned implant position and post-operative position of an implant has been used to assess accuracy. ${ }^{1}$ Studies have reported that the use of stereolithographic guides delivers predictable outcomes. ${ }^{2}$ The rigidity and precision of the surgical guide in use are deemed product related; while errors in surgical guide positioning during the surgical procedure are classified as procedure-related. Both factors attribute to a decrease in accuracy of implant position. ${ }^{3}$ Rotation of the surgical template during implant placement can occur if the guide is not adequately stable, thus increasing the risk of postoperative deviation. ${ }^{3}$

\section{Statement of the Problem:}

Inaccurate positioning and stabilization of a surgical guide during the placement of a dental implant can cause deviation between the post-operative position of the implant compared to the planned preoperative position.

\section{Significance of the Problem:}

Incorporation of a cross-arch stabilization strut in the design of the surgical guide may enhance the surgeon's ability to maintain proper seating of the guide throughout the surgical procedure. This design feature requires use of additional Dental SG Resin, increasing the costs of material. Possible inaccuracies of post-operative implant position may result from polymerization shrinkage and processing of the guide, whether or not the guide itself is more stable throughout the surgical procedure.

\section{Hypothesis:}

The post-operative position of dental implants placed using 3-D printed surgical guides utilizing the proposed stabilization strut (Group A) and the implants placed using guides without the stabilization strut (Group B) will have significant differences when compared to the planned implant position. 


\section{Null Hypothesis}

The post-operative position of dental implants placed using 3-D printed surgical guides utilizing the proposed stabilization strut (Group A) and the implants placed using guides without the stabilization strut (Group B) will have no significant differences when compared to the planned implant position.

\section{Assumptions:}

- It is assumed that the drillable maxillary models are identical.

- It is assumed that there were no misprints among the surgical guides.

\section{Limitations:}

- Sample size of twenty 3-D printed surgical guides and dental implants for statistical analysis.

- The guides were printed in two separate batches so there may be a batch-to-batch variation.

\section{Delimitations}

- The use of the proposed stabilization strut is only applicable to the maxillary arch.

- Limited to tooth-supported guides.

- The use of the proposed designed requires the extension of the guide to include adjacent dentition distal to the implant site and dentition mesially, to the contralateral canine at minimum.

- Limited to drillable surgical models. 


\section{Chapter III: Materials and Methods}

\section{Preparation for Implant Position Planning}

Twenty-one identical and drillable partially edentulous maxillary models were used for this study. The models correlate to a bone-density of type II bone per the manufacturers. One model was selected as the master model to be used for the initial CBCT and the model scan (Figure 1A). The Carestream CS 9300-1 CBCT (Carestream Dental LLC, Atlanta, Georgia) was used to obtain the initial CBCT of the master model. This data was uploaded into coDiagnostiX. (Figure 1B). The maxillary scan was then aligned in all planes. (Figure 2).
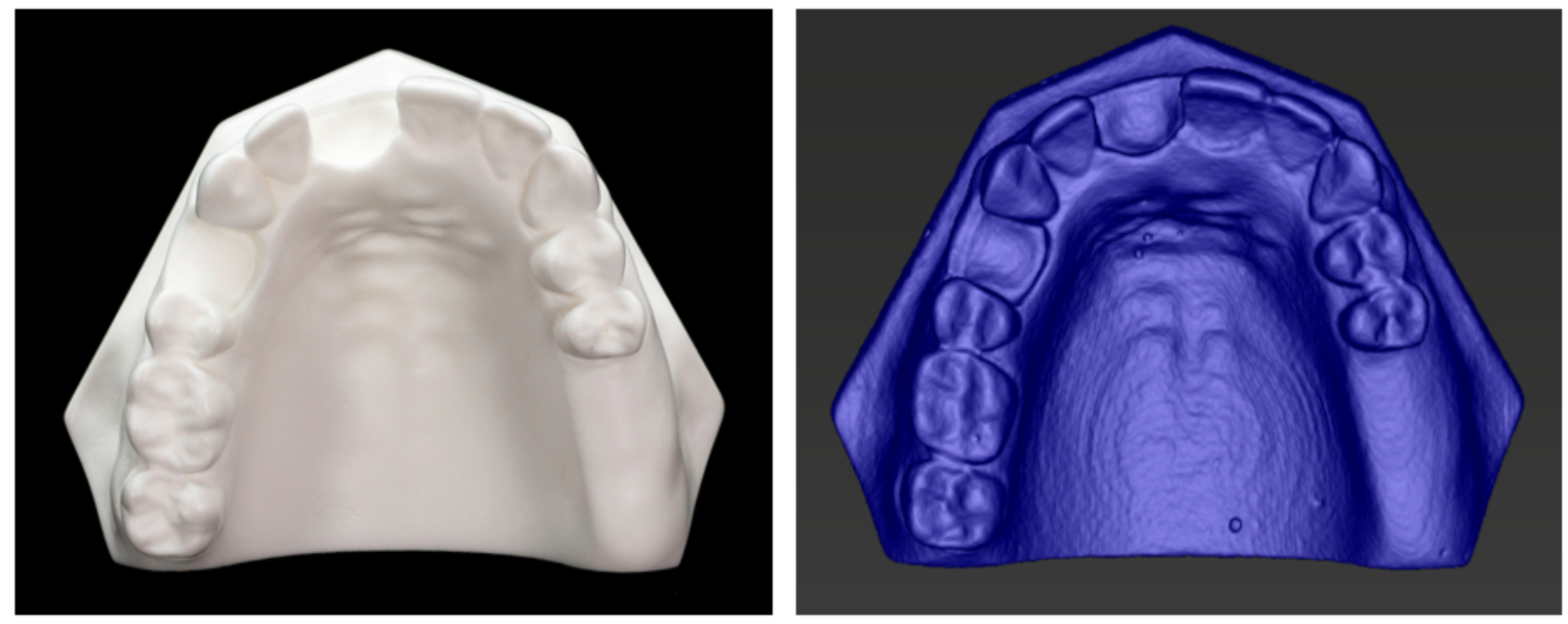

Figure 1: (A) Partially edentulous maxillary model used that correlates to Type II bone density per manufacturer (ACT/Paradigm, Escondido, CA)43; (B) Segmented DICOM file of initial CBCT scan uploaded into coDiagnostiX

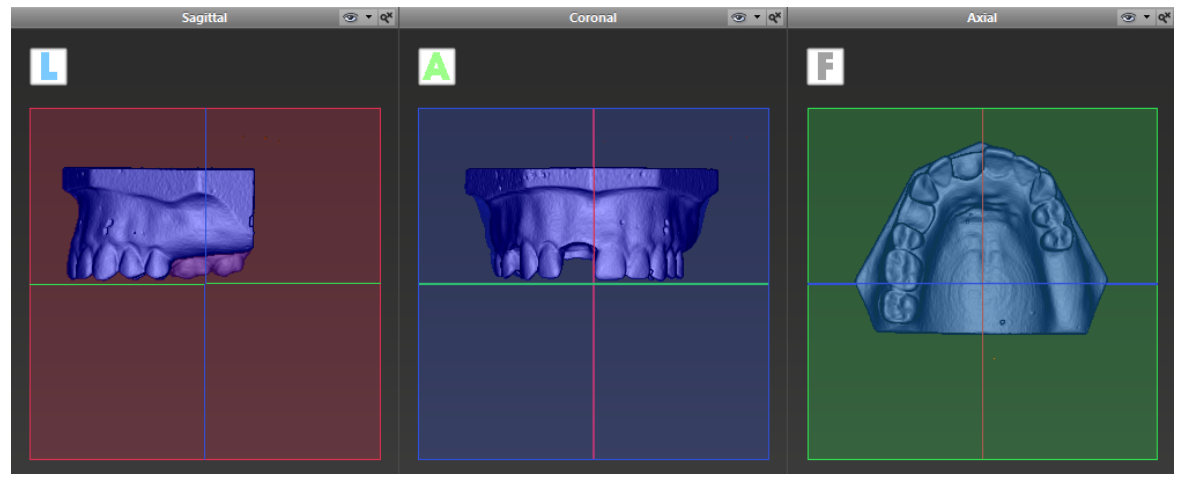

Figure 2: Alignment of Sagittal, Coronal, and Axial Planes 


\section{Fabrication of Surgical Guides}

The first surgical guide template, Group A, was designed as a tooth supported guide that incorporated a stabilization strut. The model scan view was aligned to specify the guide's path of insertion. Teeth \#2 - \#11 were selected, with the exception of the edentulous spaces \#5 and \#8 for the guide to remain solely tooth-supported. The stabilization strut was created by adding an additional tooth to the selection (\#12) and dragging it across the arch to rest on the distal occlusal surface of \#3, creating a stabilization strut spanning from \#11 to \#3.

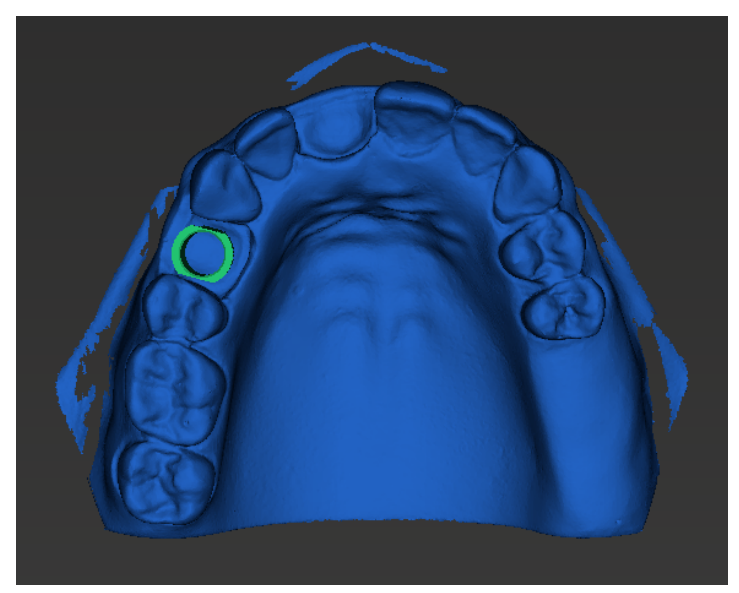

Figure 3: Path of insertion selected for the surgical guide

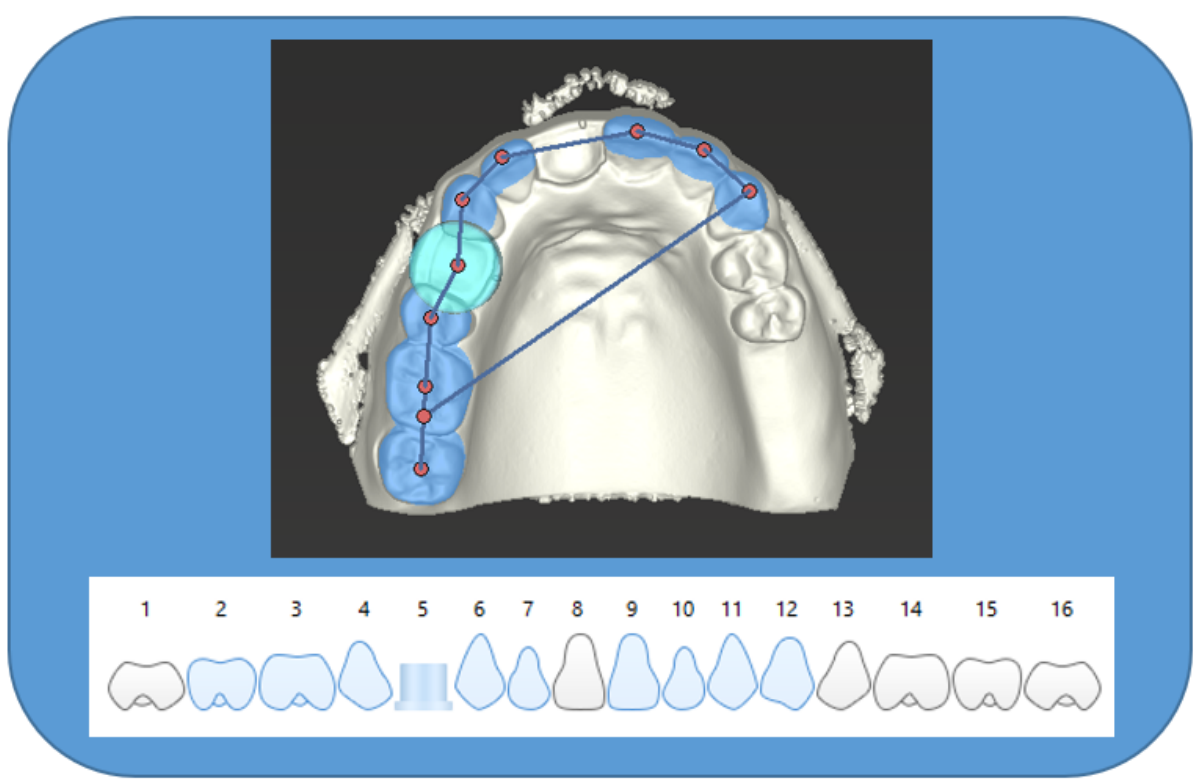

Fiqure 4: Group A surgical guides were designed to be supported by teeth \#2-4, \#6-\#7, \#9-\#11. Tooth \#12 was selected and positioned across the arch to be placed on posterior tooth \#3 for incorporation of the cross-arch stabilization strut. An additional edentulous space in area of \#8 is also present on study model. This was not selected in order for the guide to remain solely toothsupported 
Wall thickness of $3.0 \mathrm{~mm}$ was selected, and an offset of $0.15 \mathrm{~mm}$ was chosen to provide enough clearance for full seating of the surgical guides. Three inspection windows were added for easy verification of a close fit of the each guide on their assigned model.

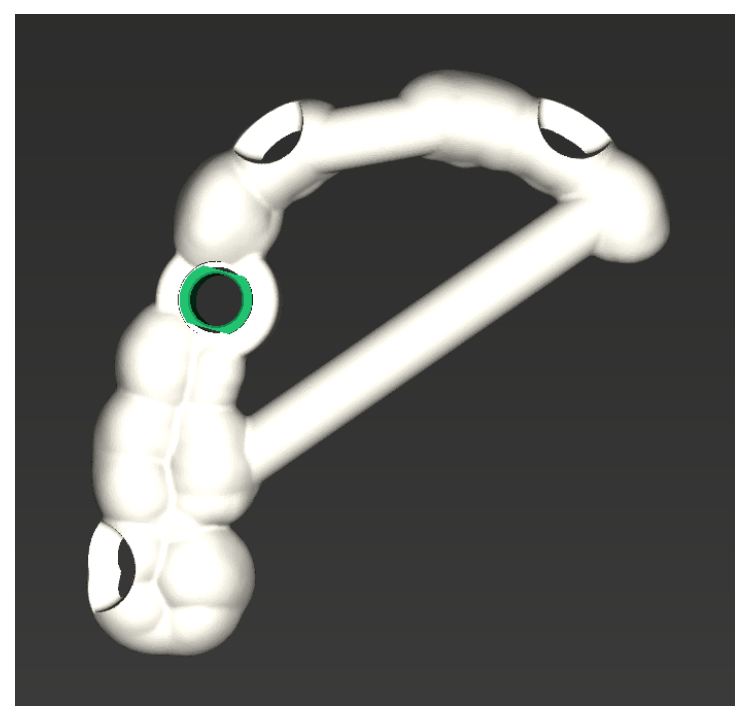

Figure 5: Visualization of the inspection windows of Group A surgical guides.

A second surgical guide (Group B) was designed based off the template of the existing guide mentioned above. All design features remained unchanged with the exception of the cross-arch stabilization strut; making the guides identical in all other aspects. The elimination of the stabilization strut required the removal of \#12 when selecting the teeth to be used for the tooth-supported guide. (Figure 6). The inspection windows also remained unchanged (Figure 7).

The two surgical guide designs, Group A and Group B, were exported into Preform. The template angulation on the build platform was adjusted equally for both groups. The position of the supports was evaluated and adjusted, assuring that the removal of the supports and the trimming process would not risk altering the fit of the guide sleeve. (Figure 9). Group A and Group B guides were then duplicated so that five guides in each group were included in the first batch of prints (ten guides total). The layout was arranged to prevent interference of the print bases. (Figure 10).

This layout on the build platform was saved on Preform and sent to the 3-D printer. Batch 1 guides were printed using the FormLabs Form 2 stereolithography (SLA) printer (FormLabs Inc., Somerville, MA). A clear UV-cured methacrylate photopolymerizing resin (Dental SG; Formlabs Inc.) material was used to print Batch 1, with use of a new Resin Tank LT and a new 
build platform. This process was repeated for fabrication of Batch 2 prints using the same layout from Batch 1, yielding a total of twenty SLA guides.

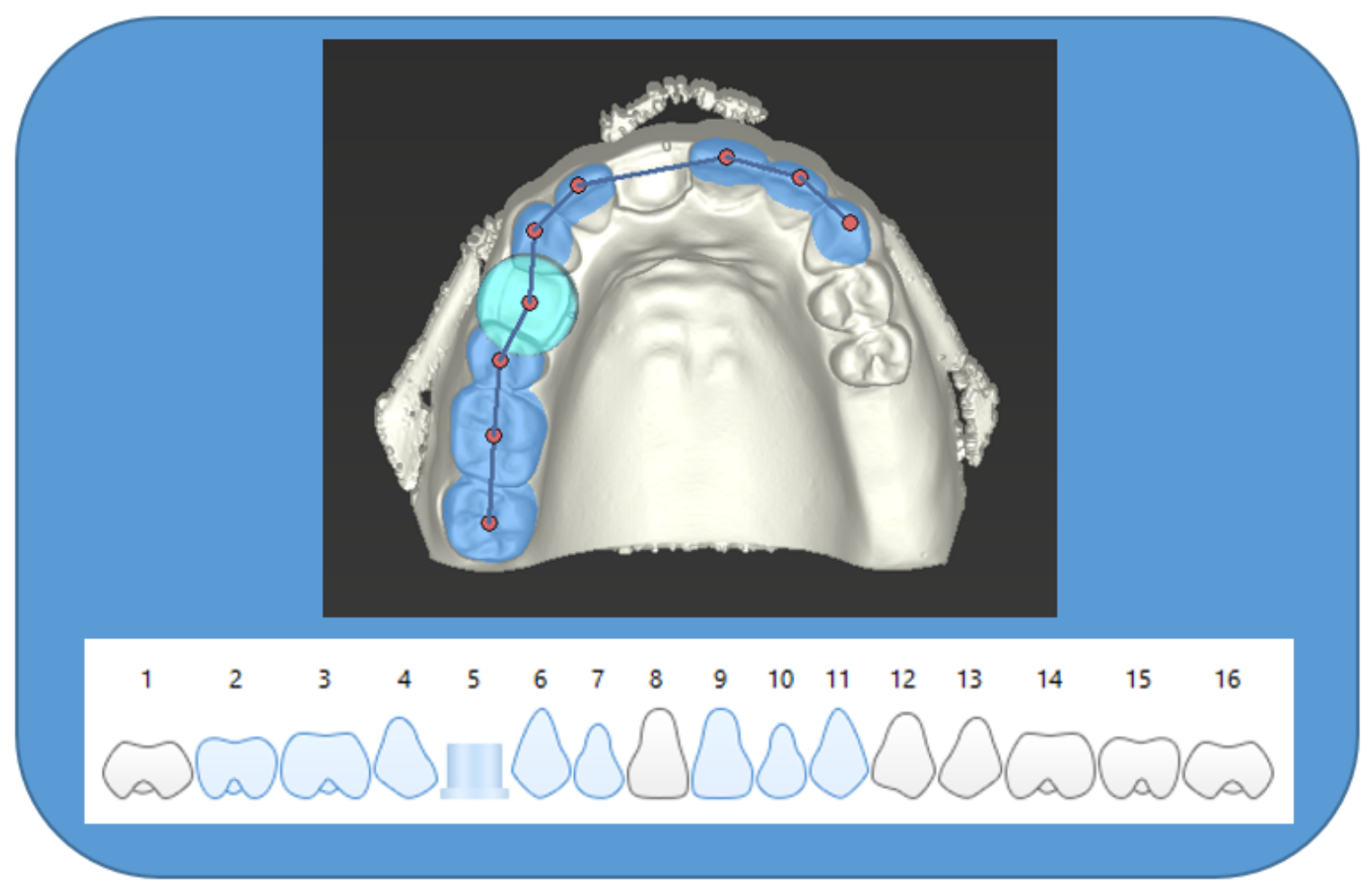

Figure 6: Elimination of the cross-arch stabilization strut in the design of Group B surgical guides.

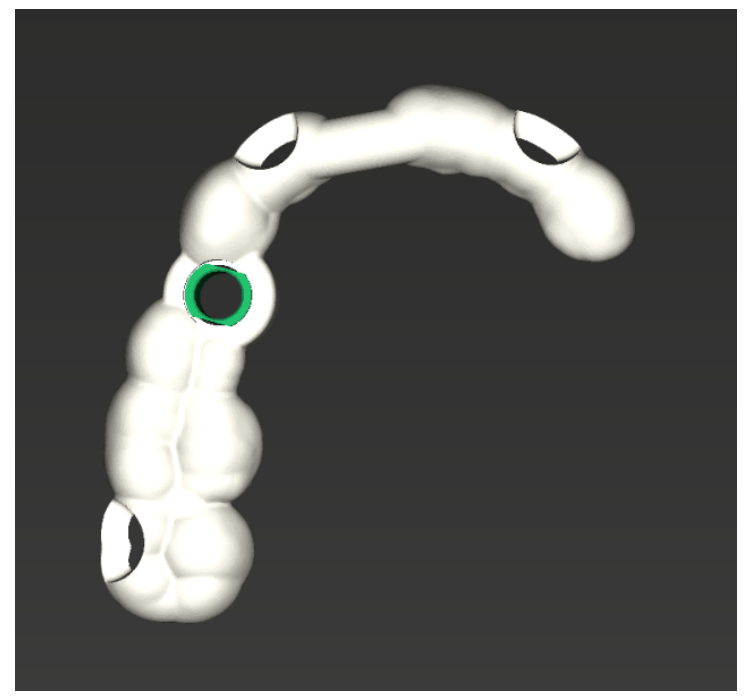

Figure 7: Visualization of inspection windows of Group B surgical guides 


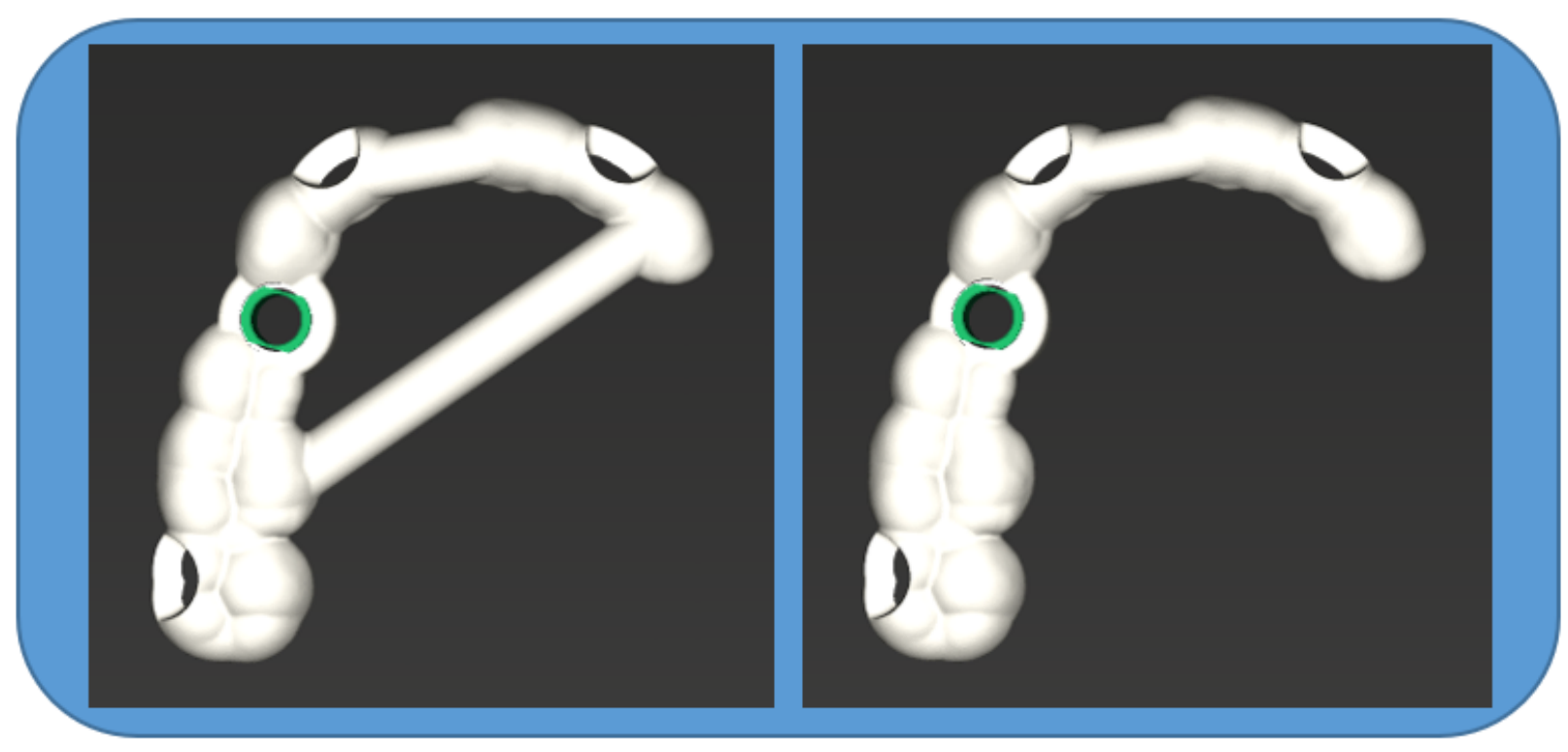

Figure 8: Side by side comparison of Group A and Group B surgical guide design

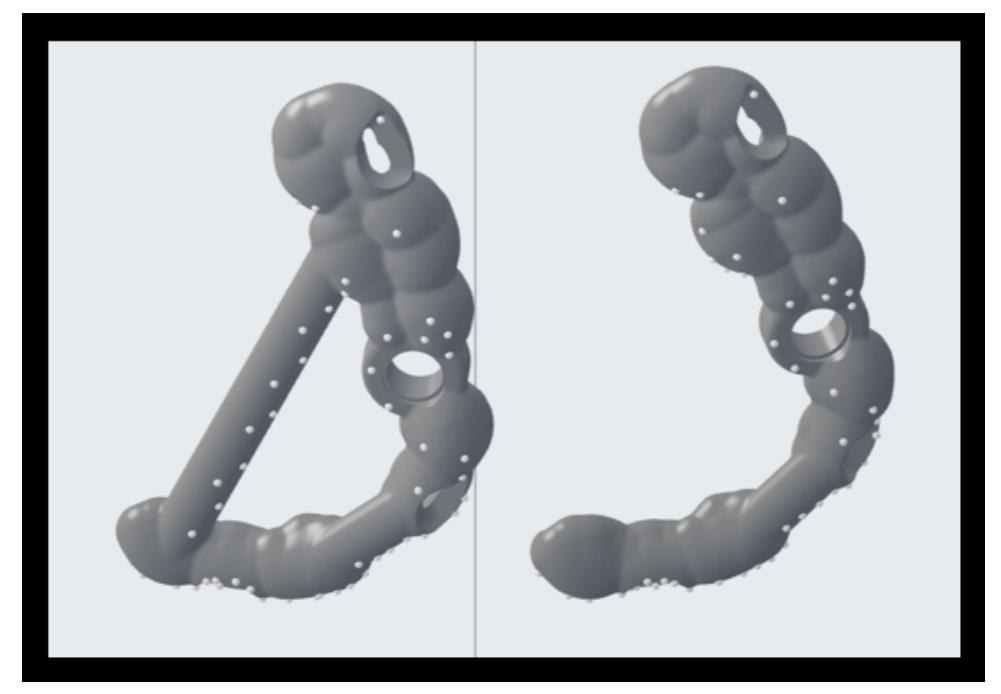

Figure 9: Angulation on build platform and location of the supports. 


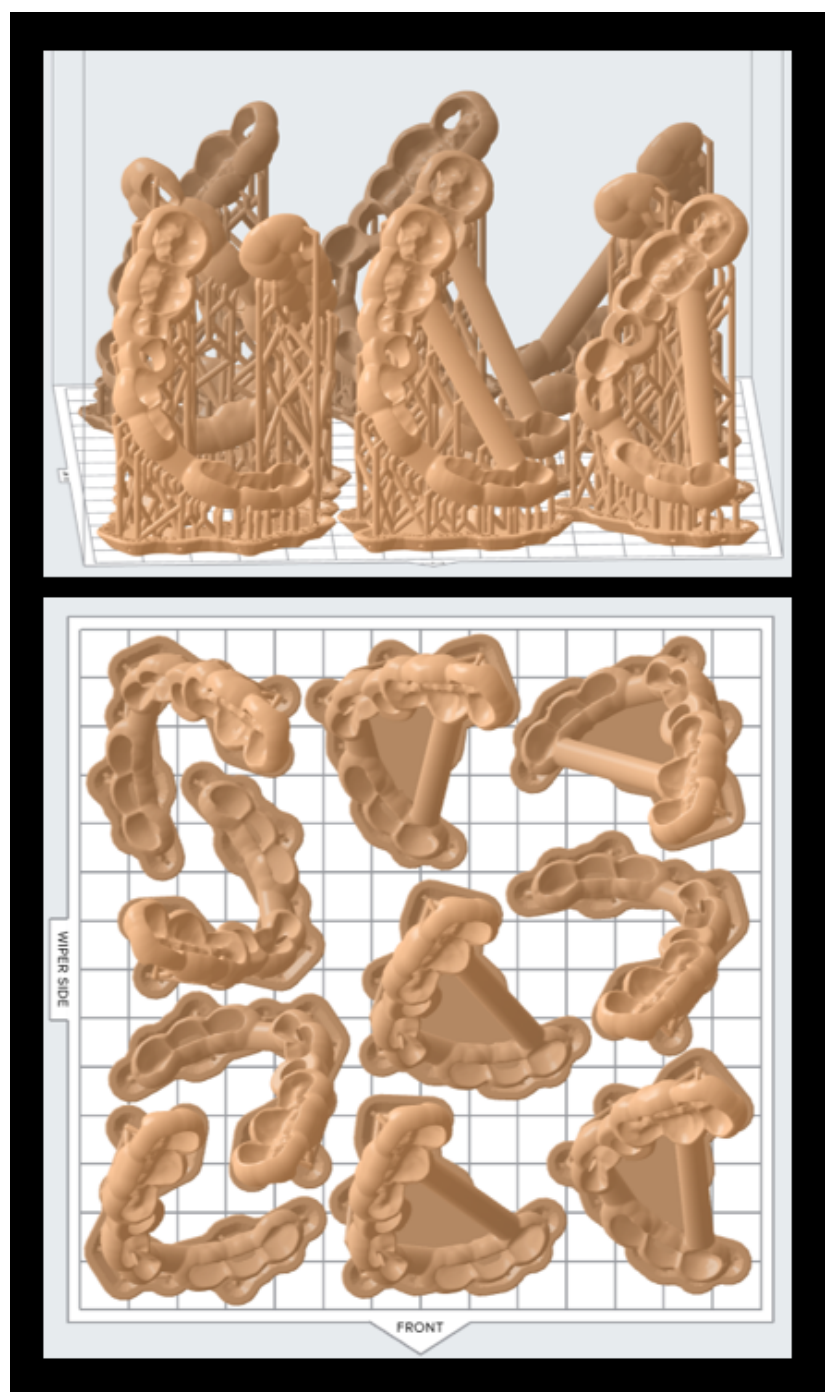

Figure 10: Layout of Batch 1 Prints including five guides in Group A and five guides in Group B (ten guides total). This Preform layout was saved and used to print Batch 2 prints so that the angulation and layout between batches remained the same.

Once the prints were complete, they were removed from the build platform (Figure 11) and soaked twice in 91\% isopropyl alcohol for ten minutes in each bath (twenty minutes total). The guides were allowed to air dry for 30 minutes prior to post-curing in the FormLabs Form Cure Oven at $60^{\circ} \mathrm{C}$ for 30 minutes, as recommended for Dental SG Resin. (Figure 12) Once the cure cycle was complete, the supports were removed with flush cutters and the guides were trimmed using Brasseler acrylic burs (Brasseler USA, Savannah, GA).

Straumann $\varnothing 5 \mathrm{~mm}$ metal sleeves (Straumann USA, LLC., Andover, MA) were inserted once finishing was complete. The guides with cross-arch stabilization struts were labeled A1 through A10, while the guides without stabilization struts were labeled B1 through B10, in the order that they were trimmed and processed. The first set of prints, Batch 1, included guides 
labeled A1 - A5 and B1 - B5, while guides labeled A6 - A10 and B6-B10 were printed in the second set of guides, Batch 2. The intaglio surface was inspected for distortions. (Figure 14). The models were assigned to each guide labeled in the same manner. The fit of each guide was evaluated on its assigned model, and no adjustments were made to the intaglio surface (Figures 15 and 16).

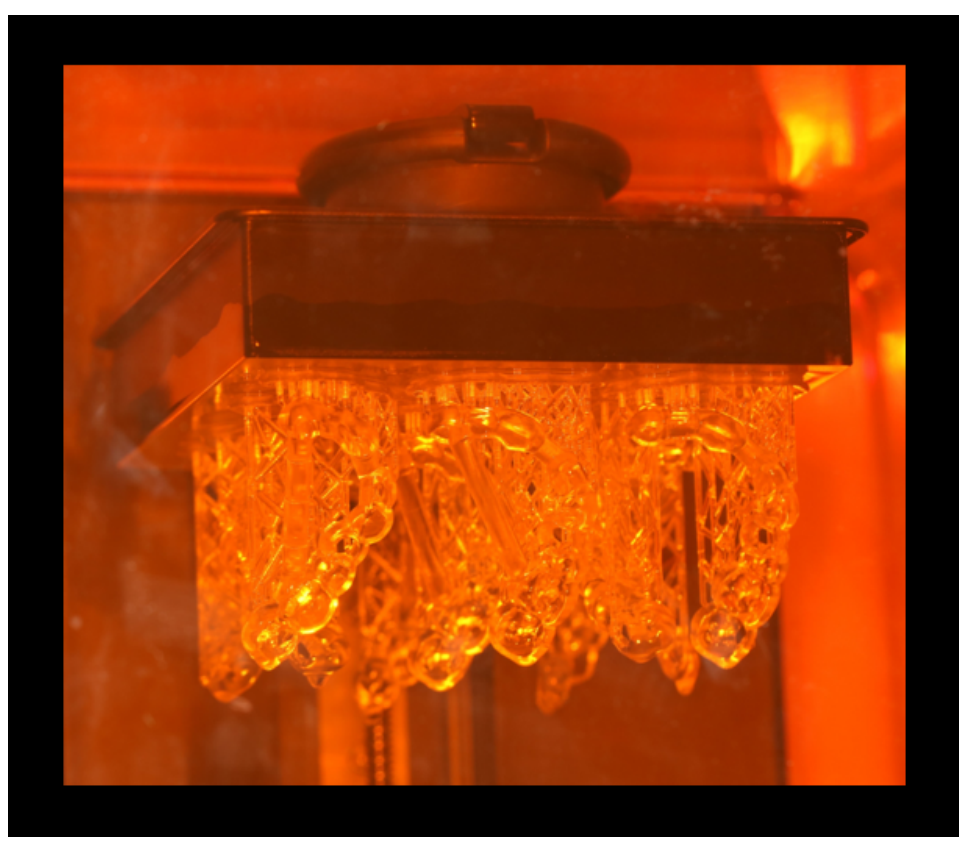

Figure 11: Finished prints remaining on build platform. 


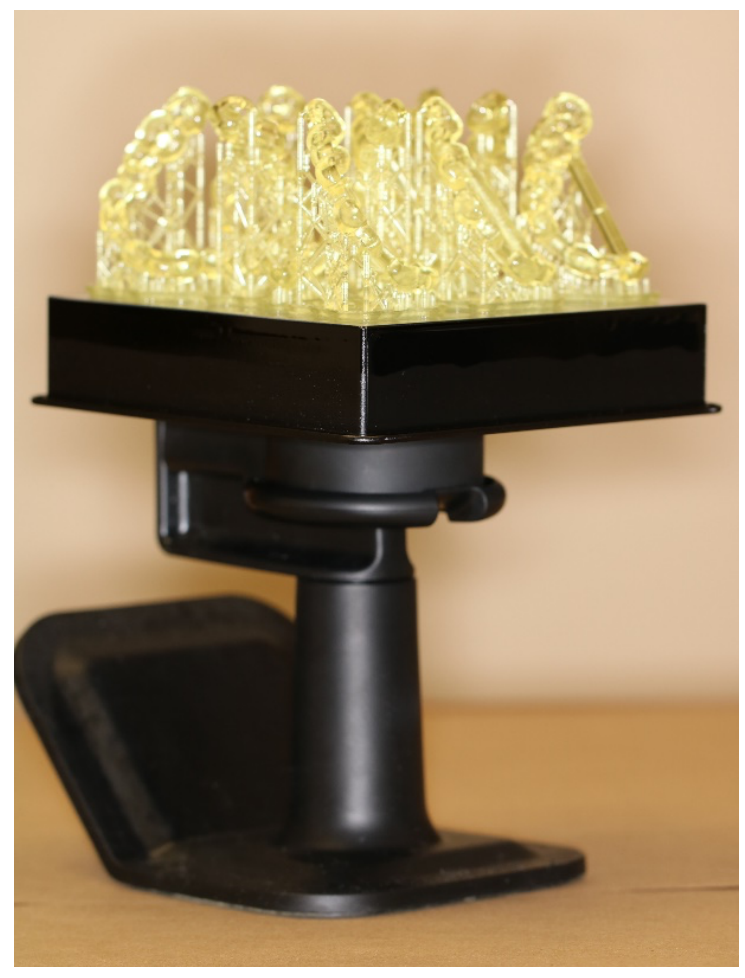

Figure 12: Build Platform after removal from Formlabs2 3D printer

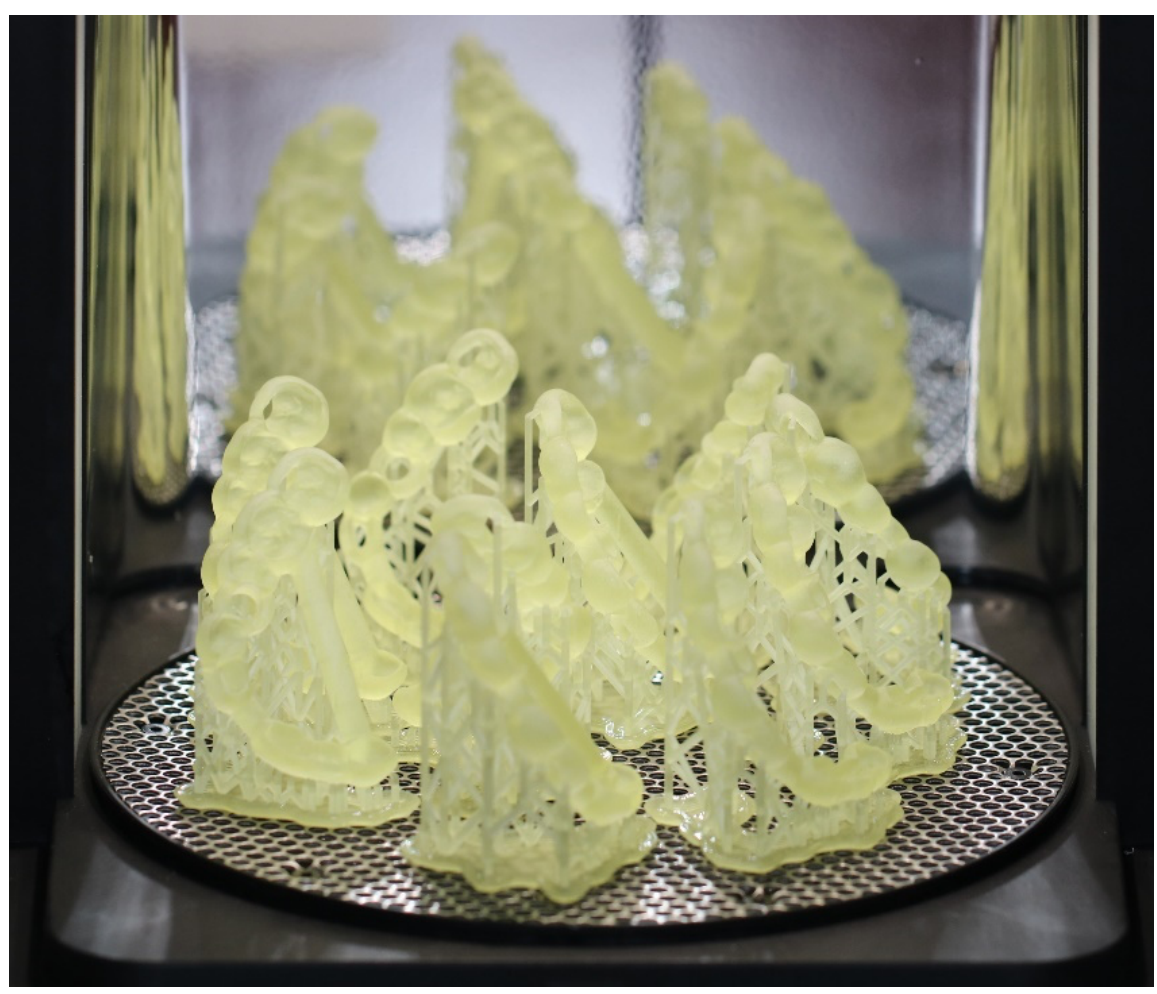

Fiqure 13: Prints cured in the FormLabs Form Cure Oven $60^{\circ} \mathrm{C}$ for 30 minutes as recommended for Dental SG Resin. 

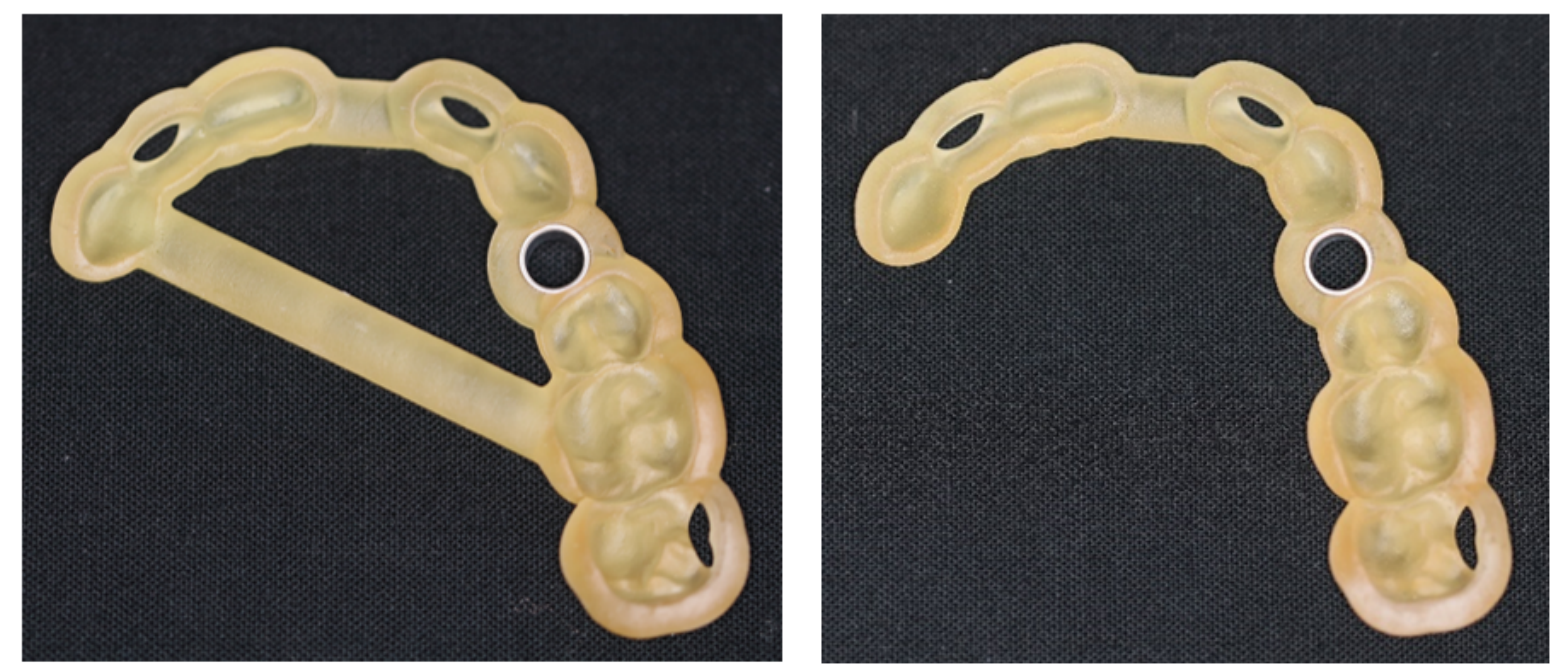

Fiqure 14: Evaluation of intaglio surface of Group $A$ and Group B surgical guides
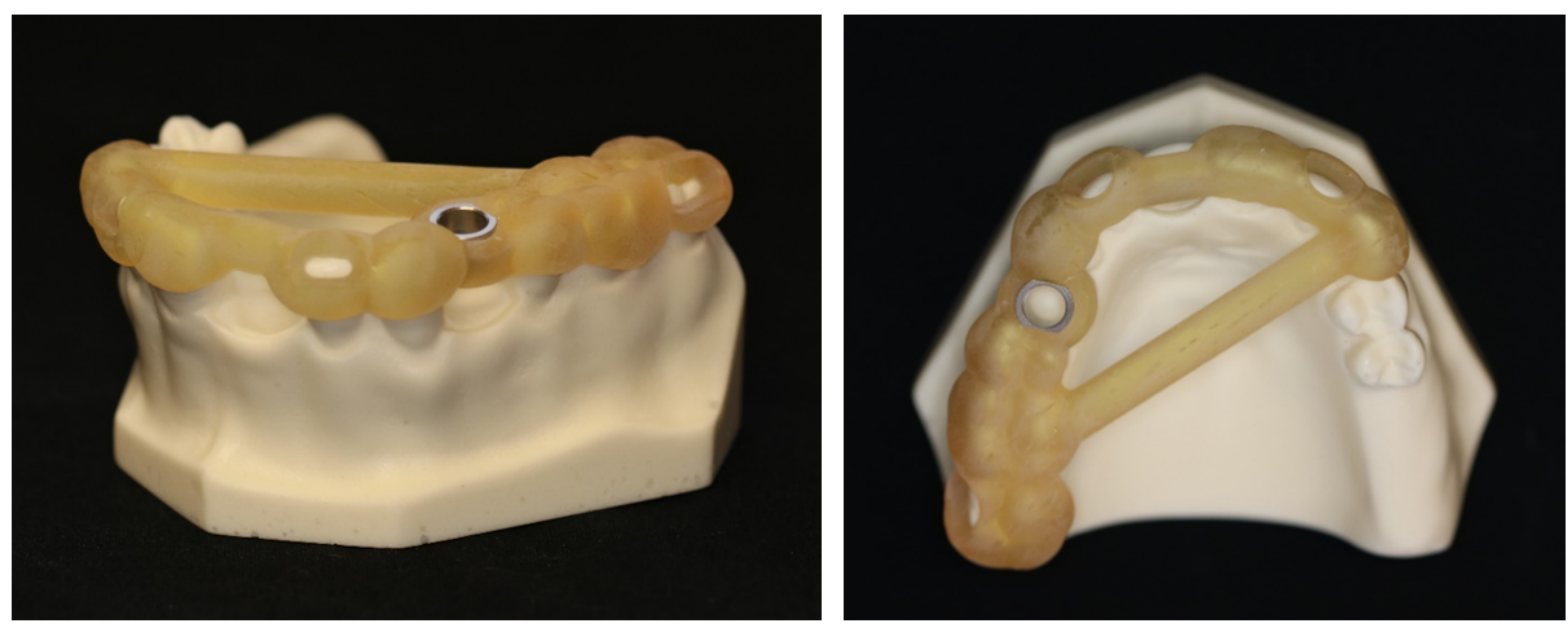

Figure 15: Group A guide assign to corresponding model 

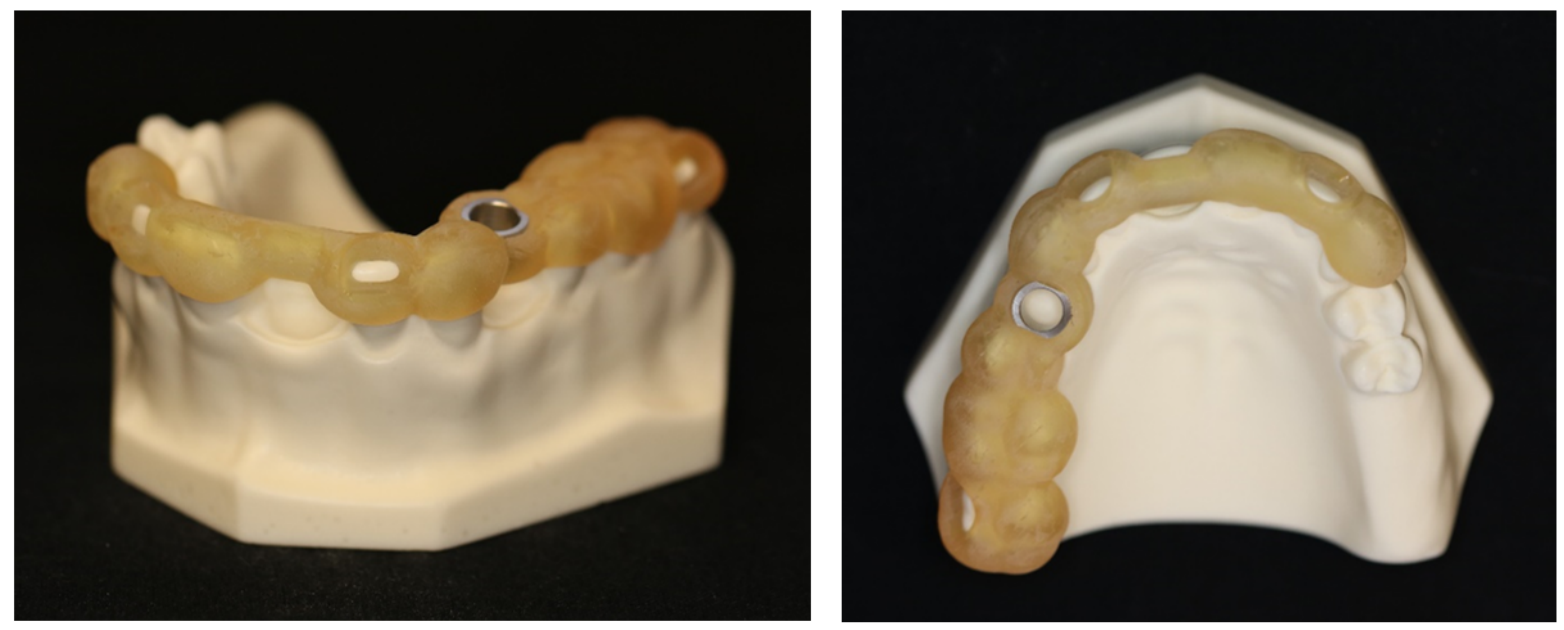

Figure 16: Group B guide assigned to corresponding model

The guides were then autoclaved, as indicated for patient use, using the Ritter M11 UltraClave autoclave (Midmark Corporation, Dayton, $\mathrm{OH}$ ). For the current study, the guides were autoclaved with use of sterilization pouches at a cycle approved for Dental SG Resin, at a temperature of $121^{\circ} \mathrm{C}$ for 15 minutes. This sterilization process was repeated for Batch 2 guides, yielding twenty autoclaved guides total.

\section{Surgical Protocol}

Twenty 3.3 x 10mm Straumann Bone Level Tapered Roxolid SLA implants were placed by the same clinician following the Straumann surgical protocol, with the exception of irrigation. The surgical guides were used to prepare the osteotomy using the $2.2 \mathrm{~mm}$ pilot drill at $800 \mathrm{RPM}$, the $2.8 \mathrm{~mm}$ pilot drill at $600 \mathrm{RPM}$ (Figure 17). Then the profile drill was used at $300 \mathrm{RPM}$. The burs were replaced after ten surgical uses. (One set of new burs were used for samples in Batch 1, and then replaced with a second set of new burs for samples in Batch 2.) Each implant was then placed free-handed at $35 \mathrm{~N} / \mathrm{cm}^{2}$ using a surgical handpiece. All implants achieved primary stability. 

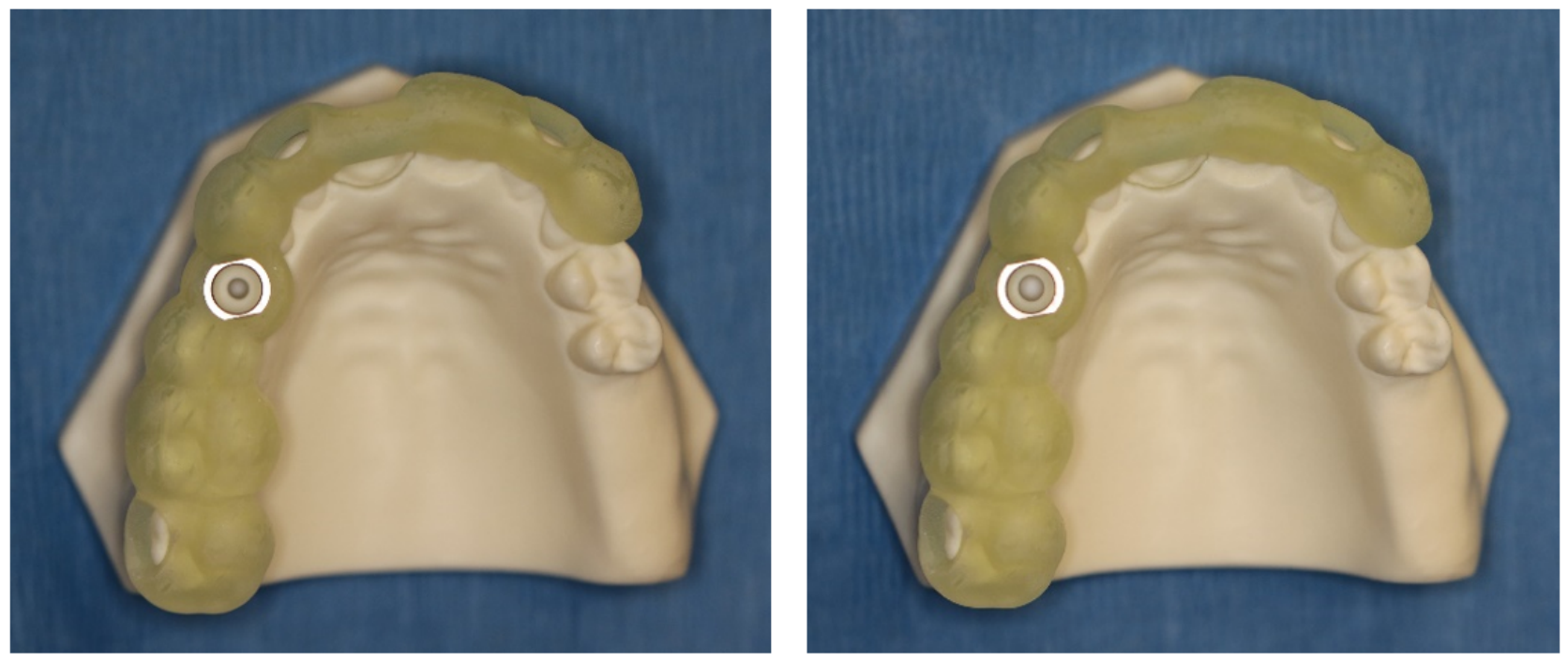

Figure 17: (A) Osteotomy created using the $2.2 \mathrm{~mm}$ pilot drill at $800 \mathrm{RPM}$, (B) Enlargement of the same osteotomy site using the $2.8 \mathrm{~mm}$ pilot drill at $600 \mathrm{RPM}$

\section{Treatment Evaluation}

Post-operative CBCTs were obtained for each model using the Carestream CS 9300-1 CBCT (Carestream Dental LLC, Atlanta, Georgia), and each scan was labeled accordingly. The data for each model was uploaded into coDiagnostiX and the treatment evaluation tool was used to merge and compare the planned implant position to the actual implant position for each sample. The data from the treatment evaluation tool in the software indicated deviations at both the implant platform (base or coronal portion) and the implant apex (tip). For both of these sites, deviations were calculated in the distal, vestibular, and apical direction. The distal value indicates a distal discrepancy when the value is positive, and a mesial discrepancy when negative. The vestibular value denotes a buccal deviation when positive, and deviation towards the lingual is indicated with negative value. A positive apical value would reveals that the 
implant was placed beyond the planned depth, while a negative value would show it was placed too shallow, short of the intended depth. The total 3-D offset calculates the hypotenuse of the three points created by the distal, vestibular, and apical data. The results were recorded for each sample and were used for analysis.

\section{Statistical Analysis:}

Statistical analysis was performed using JMP software (SAS, Cary, NC). Two comparisons were considered for the statistical analysis of the nine variables. ((Group A vs Group B) and (Batch 1 vs Batch 2)). The raw data was first evaluated for normality to guide selection of mean comparison tests. Normal curves were fitted to the data and their goodness of fit was evaluated using the Shapiro-Wilk test. 


\section{Chapter IV: Results and Discussion}

\section{Results:}

The values obtained from the treatment evaluation software for Group A and Group B samples are represented in Table 1.

\begin{tabular}{|cccccccccc|}
$\begin{array}{c}\text { Group } \\
\text { A }\end{array}$ & $\begin{array}{c}\text { Angl } \\
\boldsymbol{e}\end{array}$ & $\begin{array}{c}\text { 3D } \\
\text { Offset } \\
\text { (Base) }\end{array}$ & $\begin{array}{c}\text { Distal } \\
\text { (Base) }\end{array}$ & $\begin{array}{c}\text { Vestibular } \\
\text { (Base) }\end{array}$ & $\begin{array}{c}\text { Apical } \\
\text { (Base) }\end{array}$ & $\begin{array}{c}\text { 3D Offset } \\
\text { (Tip) }\end{array}$ & $\begin{array}{c}\text { Distal } \\
\text { (Tip) }\end{array}$ & $\begin{array}{c}\text { Vestibula } \\
\text { (Tip) }\end{array}$ & $\begin{array}{c}\text { Apical } \\
\text { (Tip) }\end{array}$ \\
\hline A1 & 1.3 & 0.19 & -0.05 & -0.01 & -0.18 & 0.31 & -0.15 & 0.2 & -0.18 \\
\hline A2 & 3.3 & 0.63 & 0.45 & 0.33 & -0.31 & 1.14 & 0.73 & 0.83 & -0.29 \\
\hline A3 & 2.3 & 0.12 & -0.07 & 0.08 & 0.06 & 0.48 & 0 & 0.47 & 0.07 \\
\hline A4 & 2.2 & 0.45 & 0 & 0.35 & -0.27 & 0.79 & 0.02 & 0.74 & -0.27 \\
\hline A5 & 1.6 & 0.24 & -0.17 & 0.17 & 0.01 & 0.48 & -0.17 & 0.45 & 0.01 \\
\hline A6 & 2.2 & 0.39 & -0.04 & 0.34 & -0.18 & 0.75 & -0.15 & 0.71 & -0.18 \\
\hline A7 & 1.7 & 0.15 & -0.05 & -0.13 & -0.06 & 0.32 & -0.31 & 0 & -0.05 \\
\hline A8 & 0.2 & 0.25 & 0.2 & -0.12 & -0.07 & 0.22 & 0.16 & -0.12 & -0.07 \\
\hline A9 & 0.9 & 0.22 & -0.07 & -0.2 & 0.03 & 0.34 & -0.22 & -0.26 & 0.03 \\
\hline A10 & 0.5 & 0.34 & -0.12 & -0.27 & -0.17 & 0.28 & -0.06 & -0.21 & -0.17 \\
\hline B1 & 2.5 & 0.51 & 0.35 & 0.17 & -0.33 & 0.87 & 0.65 & 0.48 & -0.32 \\
\hline B2 & 3.2 & 0.48 & 0.35 & 0.19 & -0.27 & 0.97 & 0.68 & 0.64 & -0.25 \\
\hline B3 & 0.9 & 0.31 & 0 & 0.1 & -0.29 & 0.38 & 0.13 & 0.2 & -0.29 \\
\hline B4 & 2.2 & 0.25 & -0.2 & -0.13 & -0.06 & 0.45 & -0.4 & 0.2 & -0.05 \\
\hline B5 & 1.3 & 0.16 & -0.14 & 0 & -0.06 & 0.36 & -0.33 & 0.13 & -0.06 \\
\hline B6 & 2.3 & 0.23 & -0.01 & 0.17 & -0.16 & 0.59 & -0.01 & 0.57 & -0.15 \\
\hline B7 & 1 & 0.3 & 0 & -0.19 & -0.24 & 0.25 & 0.08 & -0.03 & -0.24 \\
\hline B8 & 1 & 0.29 & -0.2 & -0.18 & -0.11 & 0.44 & -0.37 & -0.2 & -0.11 \\
\hline B9 & 1.3 & 0.17 & -0.11 & -0.13 & -0.03 & 0.14 & -0.11 & 0.08 & -0.03 \\
\hline B10 & 1.4 & 0.26 & -0.07 & -0.09 & -0.23 & 0.3 & -0.15 & 0.14 & -0.23 \\
\hline
\end{tabular}

Table 1: Difference measurements obtained from the treatment evaluation software for Group A and Group B samples.

The data distributions are shown in Figures A1 and A2 in the Appendix for Group A and Group B, respectively. Results for the nine values in Group A followed a normal distribution, with the exception of distal offset at both the base and the apex. In the Shapiro-Wilk test, the null hypothesis is that the data follows a normal distribution. In Group A (Figure A1), seven of the nine tests show $\mathrm{p}$ values $>.05$, indicating that the null hypothesis was upheld and the data 
indeed follow a normal distribution in these cases at the $95 \%$ confidence level. The only two cases where $\mathrm{p}<.05$ are shown with the green ovals (Distal tip and Distal base). With $\mathrm{p}<.05$, the null hypothesis is rejected and we say the data does not follow a normal distribution.

The Shapiro-Wilk test for data values in Group B are depicted in Figure A2. All are normally distributed, with the exception of the distal deviation at the base. Since most of the data is normally distributed, parametric tests (Student t-test) were used to compare group means. The Distal measurements did not follow a normal distribution so the t-test should not be used, but rather its non-parametric equivalent, the Wilcoxan. The former deals with means, the latter with medians.

The one-way analysis of deviation (or trueness) by group for all variables is shown in the box blots in Figure 18a-i. Box plots are designed according to the following principles: The line through the box represents the median, the middle half of the data (25-75\% quantiles) is within the box, the majority of the data falls between the ends of the whiskers, and a data point outside the whiskers might be an outlier. The results for two-way t-tests are also shown as the Prob $>|t|$. The results for the two-way test for all variables is $>>.05$, indicating that the null hypothesis is upheld and that there is no significant difference between the two groups at the $95 \%$ confidence level. Note that for the analysis of deviation (or trueness) for the distal base (Figure 18h) and the distal tip (Figure 18i) the t-test was not used, as it have been established that the data did not follow a normal distribution for these measurements. The non-parametric Wilcoxan test was used, but the $\mathrm{p}$-values for the 2-way analyses were again $>>.05$ indicating there is no difference between the two groups. The p-value results for all variables are summarized in Table 2.

The results for comparison of print batches are displayed in box plots shown in Figure 19a-i. Print Batch 1 includes values for Group A1-A5 and Group B1-B5 while Batch 2 includes Group A6-A10 and Group B6-B10. A significant difference between print batches was found for the angular measurement as $\mathrm{P}<.05(\mathrm{P}=.0230)$ and the null hypothesis is rejected (Figure 19a). Other significant differences between batches were observed in the vestibular base ( $P=$ $.0152)$, the vestibular apex $(\mathrm{P}=.0122)$ and the 3D Offset (Apex) measurement $(\mathrm{P}=.0311)$. No significant differences were observed between print batch for the remaining variables. Tukey Honestly Significant Difference test verified that for angular measurement, Print Batch 1 yielded a higher deviation than Print Batch $2(\mathrm{P}=.0227)$, as quite apparent from the box plot in Figure 


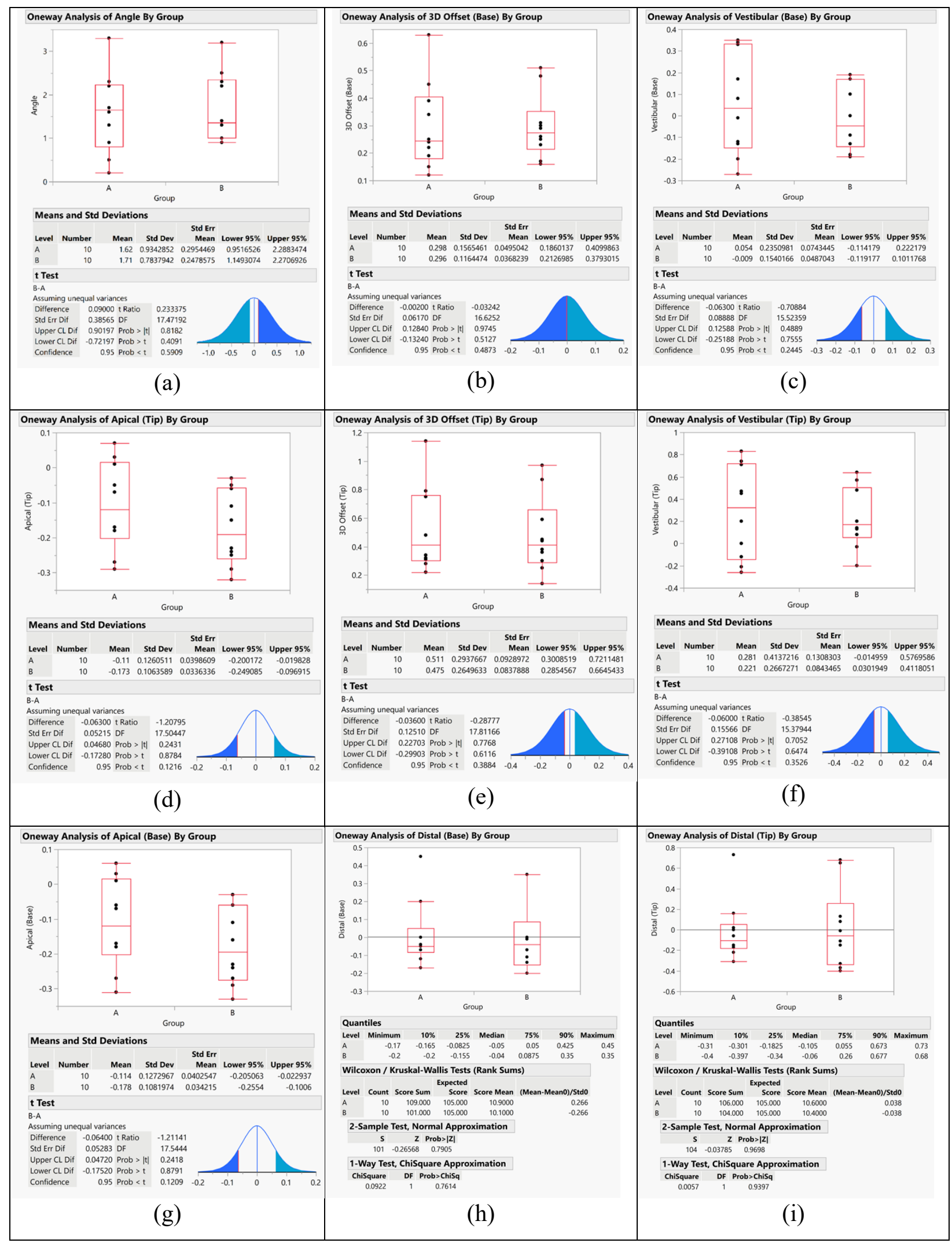

Figure 18: Comparison of means of deviation (trueness) by group for all variables. 


\begin{tabular}{|c|c|c|c|}
\hline & $\begin{array}{c}\text { Group A } \\
\text { Mean (SD) }\end{array}$ & $\begin{array}{c}\text { Group B } \\
\text { Mean (SD) }\end{array}$ & $\begin{array}{c}\text { 2-way ANOVA } \\
\text { P-value }\end{array}$ \\
\hline Angle (degrees) & $1.62(0.934)$ & $1.71(0.784)$ & .8182 \\
\hline 3D Offset (Base) & $0.298(0.157)$ & $0.296(0.116)$ & .9745 \\
\hline Distal Offset (Base) & $0.008(0.183)$ & $-0.003(0.200)$ & $.7905^{*}$ \\
\hline Vestibular Offset (Base) & $0.054(0.235)$ & $-0.009(0.154)$ & .4889 \\
\hline Apical Offset (Base) & $-0.114(0.127)$ & $-0.178(0.108)$ & .2418 \\
\hline 3D Offset (Apex) & $0.511(0.294)$ & $0.475(0.265)$ & .7768 \\
\hline Distal Offset (Apex) & $-0.015(0.294)$ & $0.017(0.387)$ & $.9698^{*}$ \\
\hline Vestibular Offset (Apex) & $0.281(0.414)$ & $0.221(0.267)$ & .7052 \\
\hline Apical Offset (Apex) & $-0.110(0.126)$ & $-0.173(0.106)$ & .2431 \\
\hline
\end{tabular}

Table 2: Summary of means, standard deviations and p-values from 2-way tests comparing means of deviations (trueness) for all variables by group. ${ }^{*}$ denotes results from non-parametric Wilcoxan test. All other results are from the parametric Student t-test.

19a. Similarly, the vestibular base deviation was observed to be significantly more positive in Print Batch $1(\mathrm{P}=.0148)$, as was the vestibular apex $(\mathrm{P}=.0116)$. The 3D offset (Apex) was also significantly more positive in Print Batch $1(\mathrm{P}=.0288)$. A summary of the 2-way ANOVA and Tukey HSD P-values comparing the print batches are provided in Table 3.

The precision with which the implants were applied was also tested, where precision is defined as the ability to observe the same measured deviation for all the different implants. This is measured by recording the difference between all combinations of deviation measurements. With 10 implants per group, a total of 45 possible measurements per group are calculated and then compared for each group. The box plots for these comparisons are given in Figure 20a-i. Only weakly significant differences between the two groups were observed at the $90 \%$ confidence level. Group A implants were applied with slightly more precision with reference to the distal base and distal apex measurements compared to those from Group B $(\mathrm{P}=.0654$ and .0720, respectively), while Group B implants demonstrated more precision in application when referencing the vestibular apex measurements $(\mathrm{P}=.0683)$. The means, standard deviations and $\mathrm{P}$-values for these measurements are all summarized in Table 4. 


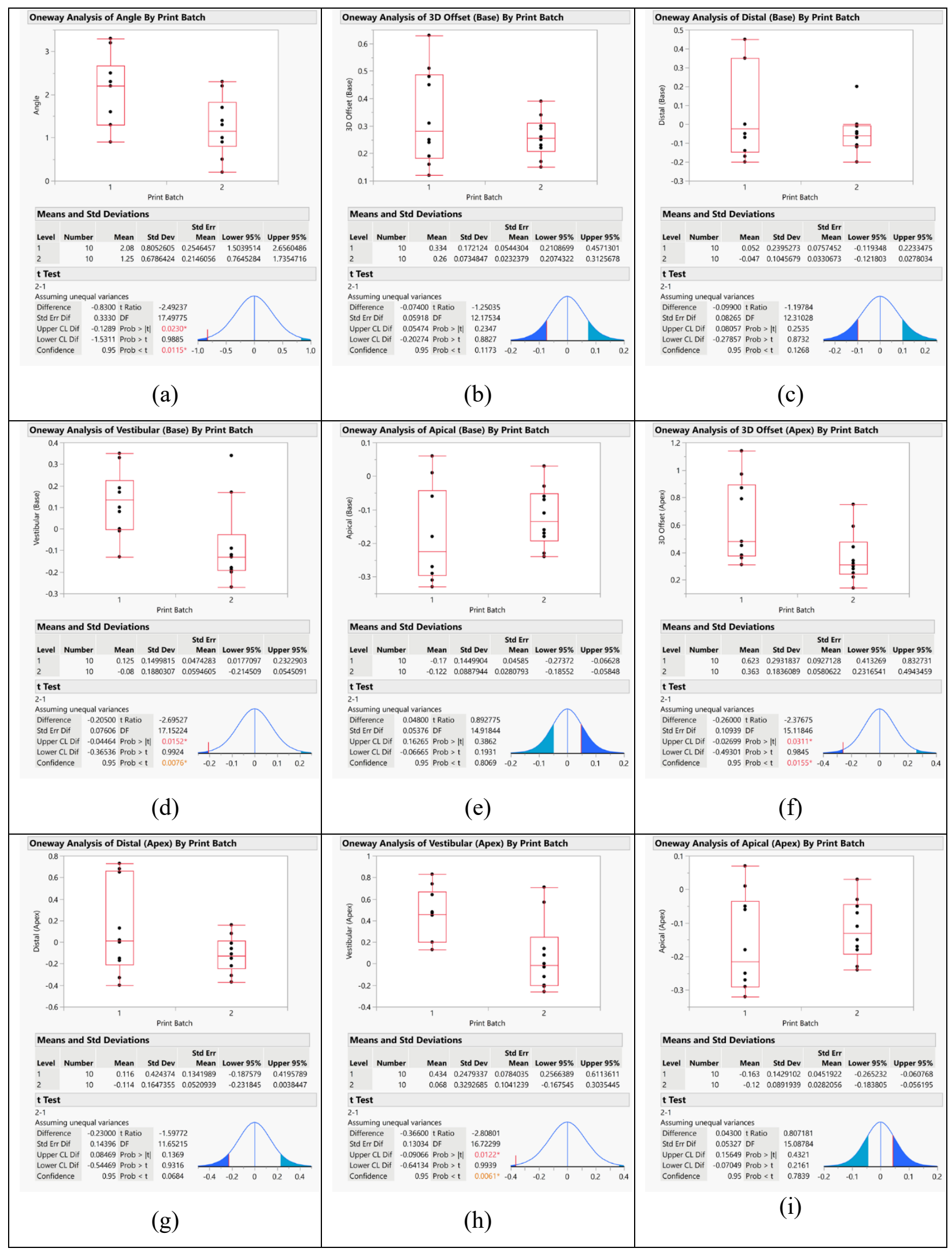

Figure 19: Comparison of means of deviation (trueness) by print batch for all variables. 


\begin{tabular}{|c|c|c|c|c|}
\hline & $\begin{array}{c}\text { Print Batch 1 } \\
\text { Mean (SD) }\end{array}$ & $\begin{array}{c}\text { Print Batch 2 } \\
\text { Mean (SD) }\end{array}$ & $\begin{array}{c}\text { 2-way ANOVA } \\
\text { P-value }\end{array}$ & $\begin{array}{c}\text { Tukey HSD } \\
\text { P-value }\end{array}$ \\
\hline Angle (degrees) & $2.08(.805)$ & $1.25(.679)$ & .0230 & .0227 \\
\hline 3D Offset (Base) & $.334(.172)$ & $.260(.074)$ & .2347 & .2272 \\
\hline Distal Offset (Base) & $.052(.240)$ & $-.047(.103)$ & .2535 & .2465 \\
\hline Vestibular Offset (Base) & $.125(.150)$ & $-.080(.188)$ & .0152 & .0148 \\
\hline Apical Offset (Base) & $-.170(.145)$ & $-.122(.089)$ & .3862 & .3838 \\
\hline 3D Offset (Apex) & $.623(.293)$ & $.363(.184)$ & .0311 & .0288 \\
\hline Distal Offset (Apex) & $.116(.424)$ & $-.114(.165)$ & .1369 & .1275 \\
\hline Vestibular Offset (Apex) & $.434(.248)$ & $.068(.329)$ & .0122 & .0116 \\
\hline Apical Offset (Apex) & $-.163(.143)$ & $-.120(.089)$ & .4321 & .4301 \\
\hline
\end{tabular}

Table 3: Summary means, standard deviations and of p-values from 2-way ANOVA and Tukey HSD tests comparing means of deviations (trueness) for all measurement variables by print batch.

\begin{tabular}{|c|c|c|c|c|}
\hline & $\begin{array}{c}\text { Print Batch 1 } \\
\text { Mean (SD) }\end{array}$ & $\begin{array}{c}\text { Print Batch 2 } \\
\text { Mean (SD) }\end{array}$ & $\begin{array}{c}\text { 2-way ANOVA } \\
\text { P-value }\end{array}$ & $\begin{array}{c}\text { Tukey HSD P- } \\
\text { value }\end{array}$ \\
\hline Angle (degrees) & $.787(1.07)$ & $.562(.966)$ & .3001 & .3000 \\
\hline 3D Offset (Base) & $.036(.221)$ & $.096(.136)$ & .1276 & .1269 \\
\hline Distal Offset (Base) & $.065(.253)$ & $.162(.236)$ & .0654 & .0654 \\
\hline Vestibular Offset (Base) & $.185(.280)$ & $.133(.174)$ & .2951 & .2945 \\
\hline Apical Offset (Base) & $-.050(.174)$ & $-.063(.141)$ & .7012 & .7012 \\
\hline 3D Offset (Apex) & $.185(.376)$ & $.245(.287)$ & .3976 & .3974 \\
\hline Distal Offset (Apex) & $.134(.398)$ & $.299(.463)$ & .0721 & .0720 \\
\hline Vestibular Offset (Apex) & $.361(.466)$ & $.205(.320)$ & .0687 & .0683 \\
\hline Apical Offset (Apex) & $-.047(.174)$ & $-.058(.141)$ & .7448 & .7448 \\
\hline
\end{tabular}

Table 4: Summary of means and standard deviations (SD) of measurements and p-values from 2way ANOVA and Tukey HSD tests comparing means of deviations (trueness) for all measurement variables by print batch. 


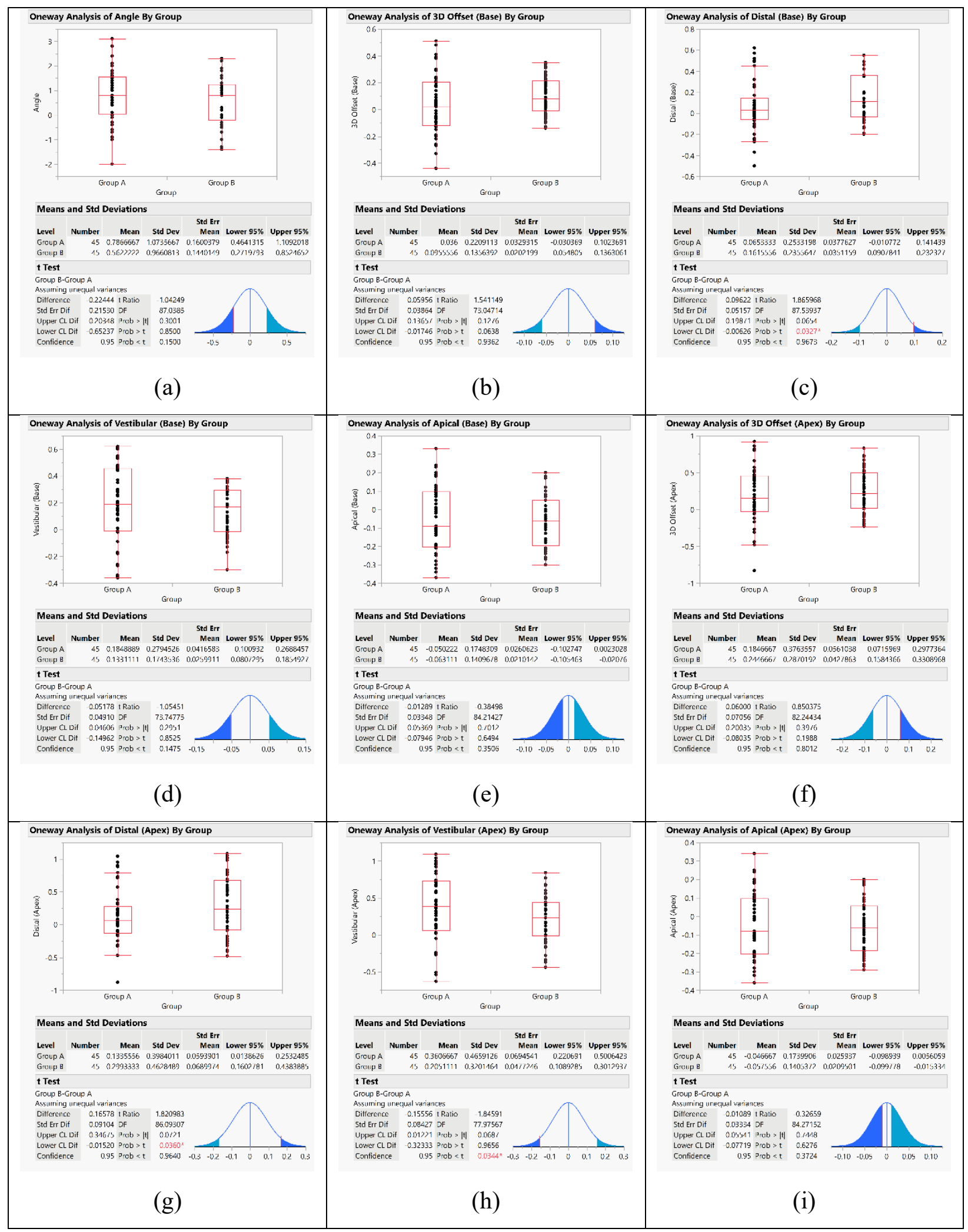

Figure 20: Comparison of precision of implants between the two groups for all measurements. 


\section{Discussion:}

The data from the treatment evaluation tool in the software indicated deviations at both the implant platform (base or coronal portion) and the implant apex (tip). For both of these sites, deviations were calculated in the distal, vestibular, and apical direction. The distal value indicated a distal discrepancy when positive, and a mesial discrepancy when negative. The vestibular value denoted a buccal deviation when positive, and a lingual deviation when negative. The apical value revealed the implant was placed beyond the planned depth when positive, and short of the intended depth when negative. The total $3 \mathrm{D}$ offset calculated hypotenuse of the three points created by the distal, vestibular, and apical data.

When comparing the results of the nine variables for implants placed utilizing surgical guides with a stabilization strut (Group A) vs the guides without the stabilization strut (Group B), no significant differences were found. The mean deviation in angle for Group A was 1.62 degrees while the mean angle deviation for Group B was 1.71 degrees. The mean distal deviation for Group A at the base was $0.008 \mathrm{~mm}$, with the positive value indicating that the implants were placed slightly distal to the planned position on average. For Group B, the average distal discrepancy was $-0.003 \mathrm{~mm}$ at the base, with the negative value of this mean indicating the implants were place slightly mesial to the planned implant position on average. These differences were still not significant. The mean values for vestibular deviation at the base for Group A was $0.054 \mathrm{~mm}$. This positive value indicates a slight buccal deviation. The mean value for vestibular deviation for Group B at the base of the implant was $-0.009 \mathrm{~mm}$, with the negative value indicating the average was placed slightly lingual compared to the average for Group A. These differences for vestibular position at the base were, however, not statistically significant. The average value for apical deviation at the base was $-0.114 \mathrm{~mm}$ and $-0.178 \mathrm{~mm}$ for Groups $\mathrm{A}$ and $\mathrm{B}$ respectively. The negative values for these averages indicate that the implants were placed short of the intended depth of the planned position. The mean $3 \mathrm{D}$ offset at the base for Group A and Group B was $0.298 \mathrm{~mm}$ and $0.296 \mathrm{~mm}$ respectively.

The mean distal deviation at the apex was $-0.015 \mathrm{~mm}$ and $0.017 \mathrm{~mm}$ for Group A and Group B respectively. The negative value for the average of Group A denotes the implants were placed slightly mesial compared to the planned position when looking at the apex. The positive 
value for the average of Group B denotes that the implants were placed slightly distal to the planned position when looking at the apex. Although, these differences are not statistically significant. The mean values for vestibular deviation at the apex for Group A was $0.281 \mathrm{~mm}$, which was not significant compare to the mean for Group B which was $0.221 \mathrm{~mm}$. The positive values for vestibular deviation do indicate a slightly buccal deviation at the apex for both groups. The average for the apical deviation at the apex was $-0.11 \mathrm{~mm}$ for Group A and $-0.173 \mathrm{~mm}$ for Group B. The negative values for these averages indicate that the implants were placed short of the intended depth of the planned position when looking at the apex. The mean 3D offset at the apex for Group A and Group B were $0.511 \mathrm{~mm}$ and $0.475 \mathrm{~mm}$ respectively, again showing not statistically significant differences.

These results are comparable to a study by Guentsch et al. ${ }^{2}$ The averages for their results in the partially guided group were an average of 1.75 degrees in angle deviation, $0.18 \mathrm{~mm} 3-\mathrm{D}$ offset at the base, $0.19 \mathrm{~mm}$ offset at the base, $0.18 \mathrm{~mm}$ buccal deviation at the base, and $0.24 \mathrm{~mm}$ apical deviation at the base. Their averages at the apex for the same partially guided group included a mean 3D offset of $0.43 \mathrm{~mm}$, distal discrepancy of $0.49 \mathrm{~mm}$, buccal deviation of $0.41 \mathrm{~mm}$, and an apical deviation of $0.24 \mathrm{~mm}$ at the apex. ${ }^{2}$

The precision with which the implants were applied did not significantly differ between the two groups. Only weakly significant differences were found at the $90 \%$ confidence level for the distal base, distal apex and vestibular apex measurements. The implants were applied with more precision in Group A in terms of both distal base and apex measurements, while Group B was slightly superior in terms of precision in the vestibular apex measurement.

The comparison of the separate prints, however, did produce some significant differences. The angle measurement is significantly greater in Print Batch $1(\mathrm{P}=.0115)$. No significant difference in 3D Offset or Distal (Base). The Vestibular (Base) measurement is significantly greater in Print Batch $1(\mathrm{P}=.0076)$, as is the 3D Offset (Apex) measurement $(\mathrm{P}=$ .0155). No significant differences were found in Apical (Base) values. The Distal (Apex) measurement is weakly significantly $(90 \%$ confidence level) greater in Print Batch $1(\mathrm{P}=.0684)$, while the Vestibular (Apex) measurement is significantly greater in Print Batch $1(\mathrm{P}=.0061)$. No significant difference in Apical (Apex) measurement. 
The significant differences between print batches, however, cannot be proven to be strictly caused by the differences in prints or processing due to the small sample size. Human error cannot be ruled out as a contributing factor since implants were placed using the Batch 1 guides first prior to placement with Batch 2 guides. Another factor at play could possibly be the use of the new build platform that had never been used prior to printing the first batch. Future studies with a larger sample size would be useful to determine whether or not one could expect significant differences in guides printed at different times.

Since no significant differences were found between Group A and B, a discussion of the differences in cost of material for the addition resin used for the stabilization strut is worth discussion. The only difference between the groups of guides tested was the utilization of the stabilization strut in Group A, meaning that less resin was needed to fabricate the guides in Group B. In order to determine the difference in cost of material between groups; the average weight of Group A and Group B guides were used in a mathematical equation. Each guide was weighed using a pennyweight scale, and the weight of the guide sleeve $(0.3 \mathrm{dwt})$ was subtracted from each. The mean weight of Group A and Group B was found to be 3.57dwt and 2.81dwt, respectively. An empty graduated cylinder was weighed prior to measuring $1 \mathrm{~mL}$ of the Dental SG Resin. The weight of the cylinder was subtracted to find that $1 \mathrm{~mL}$ of Dental SG Resin equaled 0.6dwt. According to the manufactures of the resin, $11 \mathrm{~mL}$ of Dental SG Resin costs \$4.39. ${ }^{8}$ These values were used in the following equations to determine the difference in cost of material used rounded to the nearest cent.

\section{Group A:}

$(\$ 4.39 / 11 \mathrm{~mL}) \times(1 \mathrm{~mL} / 0.6 \mathrm{dwt}) \times 3.57 \mathrm{dwt}=\$ 2.37$

\section{Group B:}

$(\$ 4.39 / 11 \mathrm{~mL}) \times(1 \mathrm{~mL} / 0.6 \mathrm{dwt}) \times 2.81 \mathrm{dwt}=\$ 1.87$

The average cost of resin material used in Group A and Group B was found to be $\$ 2.37$ and $\$ 1.87$ respectively. The difference between these two values show that the utilization of the stabilization strut in Group A raises the cost of material by $\$ 0.50$ compared to the resin used in the fabrication of Group B guides. This cost difference, however, would vary based on the 
amount of resin used depending on the size of the arch, span the strut, the design of the guide when printing guides for clinical use.

The purpose of the stabilization strut is to better allow the surgeon to keep the surgical guide fully seated throughout the surgical procedure. The guide itself must remain fully seated over all teeth that are incorporated in the tooth-supported guide. Theoretically, applying pressure to the center of the stabilization strut applies even force to both distal ends of the guide. This, however, could be affected by the design of the guide and the surgeon's experience.

The main limitation of this study is the small sample size. Another limitation worth noting would be the need to print guides in only two separate batches. On one hand, the comparison of Group A and Group B guides would be more ideal if all guides were printed and processed together. However, the comparison between print batches would be more ideal if the were more batch samples to compare.

Future areas of research could include the use stereolithographic guides utilizing the stabilization strut to place an anterior implant on the maxillary arch. Alteration to the guide design may yield interesting results when comparing L-shaped guides, U-shaped guides, and strut position changes in areas that are more or less perpendicular to the site of implant placement. The position of the cross-arch stabilization strut compared to the planned implant site and the adjacent teeth could result in differences in guide fit and stability; along with the number of adjacent teeth included in the distal extensions of the guide template. The utilization of an animal model, and/or human clinical trials, could also be used in combination with digital impressions for fabrication of the SLA surgical guides printed with and without cross-arch stabilization struts. 


\section{Chapter V: Summary and Conclusion}

\section{Summary}

The present study assessed the accuracy of implant placement using stereolithographic guides printed with and without stabilization struts by comparing the post-operative position to the planned implant position. The implant position was planned in edentulous space \#5 on a drillable model using a 3.3x10mm Bone Level Tapered (BLT) implant (Straumann). Ten surgical guides were designed utilizing a stabilization strut (Group A), while ten guides were designed without the stabilization strut (Group B). Post-operative CBCTs of the samples were used to compare the implant position to the planned position using treatment evaluation software.

When comparing the results of the nine variables for implants placed utilizing surgical guides with a stabilization strut (Group A) vs the guides without the stabilization strut (Group B), no significant differences were found. The mean deviation in angle for Group A was 1.62 degrees while the mean angle deviation for Group B was 1.71 degrees. The precision with which the implants were applied did not significantly differ between the two groups. Only weakly significant differences were found at the $90 \%$ confidence level for the distal base, distal apex and vestibular apex measurements. The implants were applied with more precision in Group A in terms of both distal base and apex measurements, while Group B was slightly superior in terms of precision in the vestibular apex measurement.

The comparison of the separate prints, however, did produce some significant differences. The angle measurement is significantly greater in Print Batch $1(\mathrm{P}=.0115)$. The Vestibular (Base) measurement is significantly greater in Print Batch $1(\mathrm{P}=.0076)$, as is the 3D Offset (Apex) measurement ( $\mathrm{P}=.0155)$. No significant differences were found in Apical (Base) values. The Distal (Apex) measurement is weakly significantly ( $90 \%$ confidence level) greater in Print Batch $1(\mathrm{P}=.0684)$, while the Vestibular (Apex) measurement is significantly greater in Print Batch $1(\mathrm{P}=.0061)$. The small sample size, however, cannot prove the significant differences to be clinically significant between print batches.

The main finding of this study was that no significant differences were found in the position of implants placed utilizing surgical guides with a stabilization strut (Group A) vs the guides without the stabilization strut (Group B). The null hypothesis is upheld. 


\section{Conclusion}

- The main finding of this study was that no significant differences were found in the position of implants placed utilizing surgical guides with a stabilization strut (Group A) vs the guides without the stabilization strut (Group B). The null hypothesis is upheld.

- The comparison of the separate prints, however, did produce some significant differences.

- The angle measurement is significantly greater in Print Batch $1(\mathrm{P}=.0115)$. The Vestibular (Base) measurement is significantly greater in Print Batch $1(\mathrm{P}=$ .0076), as is the 3D Offset (Apex) measurement $(\mathrm{P}=.0155)$.

- No significant differences were found in Apical (Base) values.

- The Distal (Apex) measurement is weakly significantly (90\% confidence level) greater in Print Batch $1(\mathrm{P}=.0684)$, while the Vestibular (Apex) measurement is significantly greater in Print Batch $1(\mathrm{P}=.0061)$.

- The small sample size, however, cannot prove the significant differences to be clinically significant between print batches.

- The difference in cost of materials for the additional resin used to fabricate Group A guides compared to Group B guides was calculated to be $\$ 0.50$.

- This cost difference, however, would vary based on the amount of resin used depending on the size of the arch, span the strut, the design of the guide when printing guides for clinical use.

- Comparable accuracy, slight increase in cost of materials, and the possibility of reduction in surgical time warrants future research for the proposed design for 3-D printed surgical guides. 


\section{References}

1. Putra RH, Yoda N, Astuti ER, Sasaki K. The accuracy of implant placement with computerguided surgery in partially edentulous patients and possible influencing factors: A systematic review and meta-analysis. J Prosthodont Res. 2021 Jan 26. doi: 10.2186/jpr.JPR_D_20_00184. Epub ahead of print. PMID: 33504723.

2. Guentsch, A., Sukhtankar, L., An, H., \& Luepke, P. G. (2020). Precision and trueness of implant placement with and without static surgical guides: An in vitro study. The Journal of Prosthetic Dentistry. doi:10.1016/j.prosdent.2020.06.015

3. Cassetta M, Di Mambro A, Giansanti M, Stefanelli LV, Cavallini C. 2013. The intrinsic error of a stereolithographic surgical template in implant guided surgery. Int J Oral Maxillofac Surg. 42(2):264-275.47

4. Hämmerle, C. H., \& Tarnow, D. (2018). The etiology of hard- and soft-tissue deficiencies at dental implants: A narrative review. Journal of Clinical Periodontology, 45. doi:10.1111/jcpe. 12955

5. Romanos GE, Delgado-Ruiz R, Sculean A. Concepts for prevention of complications in implant therapy. Periodontology 2000. 2019 Oct;81(1):7-17. doi: 10.1111/prd.12278. PMID: 31407435.

6. Smith PN, Palenik CJ, Blanchard SB. Microbial contamination and the sterilization/disinfection of surgical guides used in the placement of endosteal implants. Int $\mathbf{J}$ Oral Maxillofac Implants. 2011 Mar-Apr;26(2):274-81. PMID: 21483880.

7. Török G, Gombocz P, Bognár E, Nagy P, Dinya E, Kispélyi B, Hermann P. Effects of disinfection and sterilization on the dimensional changes and mechanical properties of $3 \mathrm{D}$ printed surgical guides for implant therapy - pilot study. BMC Oral Health. 2020 Jan 23;20(1):19. doi: 10.1186/s12903-020-1005-0. PMID: 31973705; PMCID: PMC6979289.

8. Whitley D, Bencharit S. 2015. Digital implantology with desktop 3d printing.:

Formlabs White Paper. p. 1-15.

9. Mora MA, Chenin DL, Arce RM. 2014. Software tools and surgical guides in dentalimplantguided surgery. Dent Clin North Am. 58(3):597-626.

10. Kühl S, Zürcher S, Mahid T, Müller-Gerbl M, Filippi A, Cattin P. 2013. Accuracy of full guided vs. Half-guided implant surgery. Clin Oral Implants Res. 24(7):763-769.

11. Zhou W, Liu Z, Song L, Kuo CL, Shafer DM. 2018. Clinical factors affecting the accuracy of guided implant surgery-a systematic review and meta-analysis. J Evid Based Dent Pract. 18(1):28-40. 
12. Dreiseidler T, Neugebauer J, Lingohr T, Rothamel D, Mischkowski RA, Zöller JE. 2009. Accuracy of a newly developed integrated system for dental implant planning. Clinical oral implants research. p. 1191 - 1199.

13. Cassetta M, Stefanelli LV, Giansanti M, Calasso S. 2012. Accuracy of implant placement with a stereolithographic surgical template. Int J Oral Maxillofac Implants. 27(3):655-663.

14. Cassetta M, Giansanti M, Di Mambro A, Calasso S, Barbato E. 2013. Accuracy of two stereolithographic surgical templates: A retrospective study. Clin Implant Dent Relat Res. 15(3):448-459.

15. Turbush SK, Turkyilmaz I. 2012. Accuracy of three different types of stereolithographic surgical guide in implant placement: An in vitro study. J Prosthet Dent. 108(3):181-188.50

16. Ozan O, Turkyilmaz I, Ersoy AE, McGlumphy EA, Rosenstiel SF. 2009. Clinical accuracy of 3 different types of computed tomography-derived stereolithographic surgical guides in implant placement. J Oral Maxillofac Surg. 67(2):394-401.

17. Bover-Ramos F, Viña-Almunia J, Cervera-Ballester J, Peñarrocha-Diago M, GarcíaMira B. 2018. Accuracy of implant placement with computer-guided surgery: A systematic review and meta-analysis comparing cadaver, clinical, and in vitro studies. Int J Oral Maxillofac Implants. 33(1):101-115.

18. ISO-5725-1:1994 (E). Accuracy (trueness and precision) of measurement methods and results - part 1: general principles and definitions. Geneva: International Organization for Standardization; 2018. ISO Store Order: OP- 449776 (Date: 2020-06-18). Available at: http://www.iso.org/iso/home.html.

19. Scherer MD. 2014. Presurgical implant-site assessment and restoratively driven digital planning. Dent Clin North Am. 58(3):561-595.

20. Jacobs R, Quirynen M. 2014. Dental cone beam computed tomography: Justification for use in planning oral implant placement. Periodontol 2000. 66(1):203-213.

21. Hatcher DC, Dial C, Mayorga C. 2003. Cone beam ct for pre-surgical assessment of implant sites. J Calif Dent Assoc. 31(11):825-833.

22. Wyatt CC, Pharoah MJ. 1998. Imaging techniques and image interpretation for dental implant treatment. Int J Prosthodont. 11(5):442-452.

23. Hassan B, Couto Souza P, Jacobs R, de Azambuja Berti S, van der Stelt P. 2010. Influence of scanning and reconstruction parameters on quality of three-dimensional surface models of the dental arches from cone beam computed tomography. Clin Oral Investig. 14(3):303-310. 
24. Koenig LJ. 2015. Imaging of the jaws. Semin Ultrasound CT MR. 36(5):407-414.

25. Scarfe WC, Farman AG. 2008. What is cone-beam ct and how does it work? Dent Clin North Am. 52(4):707-730, v.

26. Araki K, Patil S, Endo A, Okano T. 2013. Dose indices in dental cone beam ct and correlation with dose-area product. Dentomaxillofac Radiol. 42(5):20120362.

27. Widmann G, Fischer B, Berggren JP, Dennhardt A, Schullian P, Reto B, Puelacher W. 2016. Cone beam computed tomography vs multislice computed tomography in computer-aided design/computer-assisted manufacture guided implant surgery based on three-dimensional optical scanning and stereolithographic guides: Does image modality matter? Int J Oral Maxillofac Implants. 31(3):527-533.

28. Accuracy and reproducibility of four cone beam computed tomography devices using $3 \mathrm{~d}$ implant-planning software. 48

29. Dreiseidler T, Tandon D, Kreppel M, Neugebauer J, Mischkowski RA, Zinser MJ, Zöller JE. 2012. Cbct device dependency on the transfer accuracy from computeraided implantology procedures. Clin Oral Implants Res. 23(9):1089-1097.

30. Affairs ADACoS. 2012. The use of cone-beam computed tomography in dentistry: An advisory statement from the american dental association council on scientific affairs. J Am Dent Assoc. 143(8):899-902.

31. Hatcher DC. 2010. Operational principles for cone-beam computed tomography. $\mathrm{J}$ Am Dent Assoc. 141 Suppl 3:3S-6S.

32. Naziri E, Schramm A, Wilde F. 2016. Accuracy of computer-assisted implant placement with insertion templates. GMS Interdiscip Plast Reconstr Surg DGPW. 5:Doc15.

33. Scherer MD. 2014. Presurgical implant-site assessment and restoratively driven digital planning. Dent Clin North Am. 58(3):561-595.

34. Flügge T, Derksen W, Te Poel J, Hassan B, Nelson K, Wismeijer D. 2017. Registration of cone beam computed tomography data and intraoral surface scans - a prerequisite for guided implant surgery with cad/cam drilling guides. Clin Oral Implants Res. 28(9):1113-1118.

35. Tahayeri A, Morgan M, Fugolin AP, Bompolaki D, Athirasala A, Pfeifer CS, Ferracane JL, Bertassoni LE. 2018. 3d printed versus conventionally cured provisional crown and bridge dental materials. Dent Mater. 34(2):192-200.

36. Reyes A, Turkyilmaz I, Prihoda TJ. 2015. Accuracy of surgical guides made from conventional and a combination of digital scanning and rapid prototyping 
techniques. J Prosthet Dent. 113(4):295-303.

37. Whitley D, Eidson RS, Rudek I, Bencharit S. 2017. In-office fabrication of dental implant surgical guides using desktop stereolithographic printing and implant treatment planning software: A clinical report. J Prosthet Dent. 118(3):256-263.

38. Noharet R, Pettersson A, Bourgeois D. 2014. Accuracy of implant placement in the posterior maxilla as related to 2 types of surgical guides: A pilot study in the human cadaver. J Prosthet Dent. 112(3):526-532.

39. Park C, Raigrodski AJ, Rosen J, Spiekerman C, London RM. 2009. Accuracy of implant placement using precision surgical guides with varying occlusogingival heights: An in vitro study. J Prosthet Dent. 101(6):372-381.

40. Whitley D, Bencharit S. 2019 Intro to Stereolithography 3D Printing. Formlabs White Paper. p. $1-18$

41. Dawood A, Marti Marti B, Sauret-Jackson V, Darwood A. 3D printing in dentistry. Br Dent J. 2015 Dec;219(11):521-9. doi: 10.1038/sj.bdj.2015.914. Erratum in: Br Dent J. 2016 Jan 22;220(2):86.

42. Torabi K, Farjood E, Hamedani S. Rapid Prototyping Technologies and their Applications in Prosthodontics, a Review of Literature. J Dent (Shiraz). 2015 Mar;16(1):1-9. PMID: 25759851; PMCID: PMC4345107.

43. Ds-04 Surgical Training Maxilla. (n.d.). https://paradigmmodels.com/product/surgicaltraining-maxilla/. photograph. 


\section{Appendix}

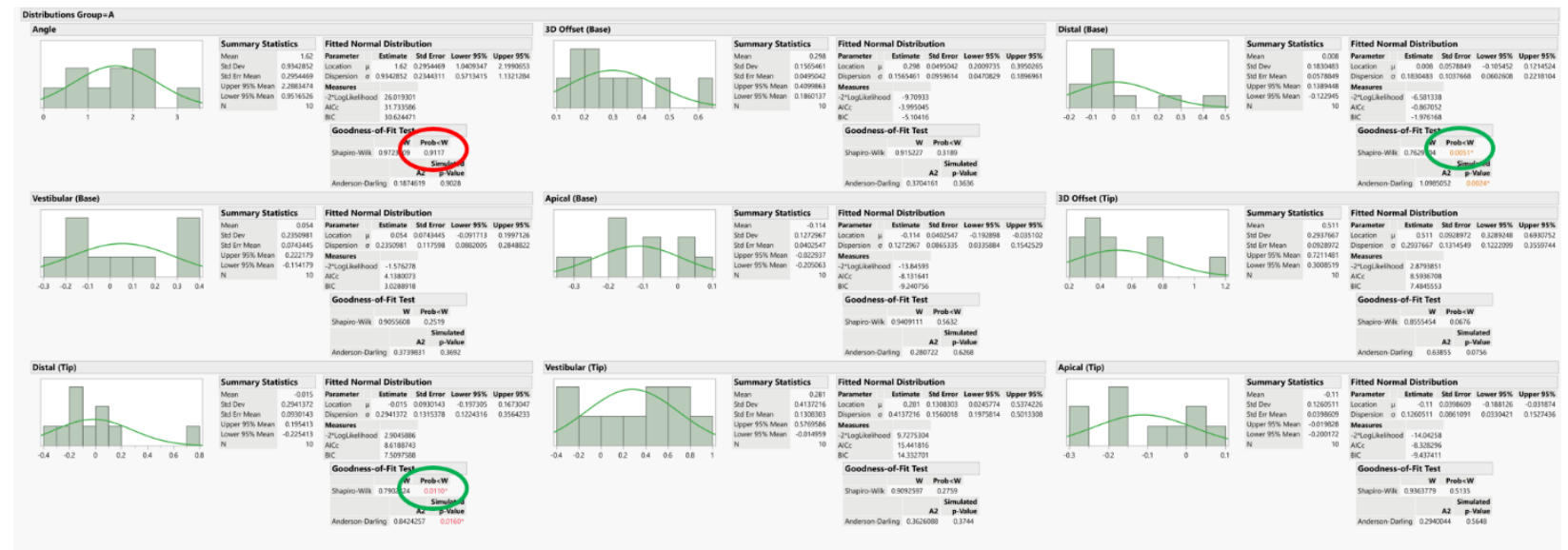

Figure A1

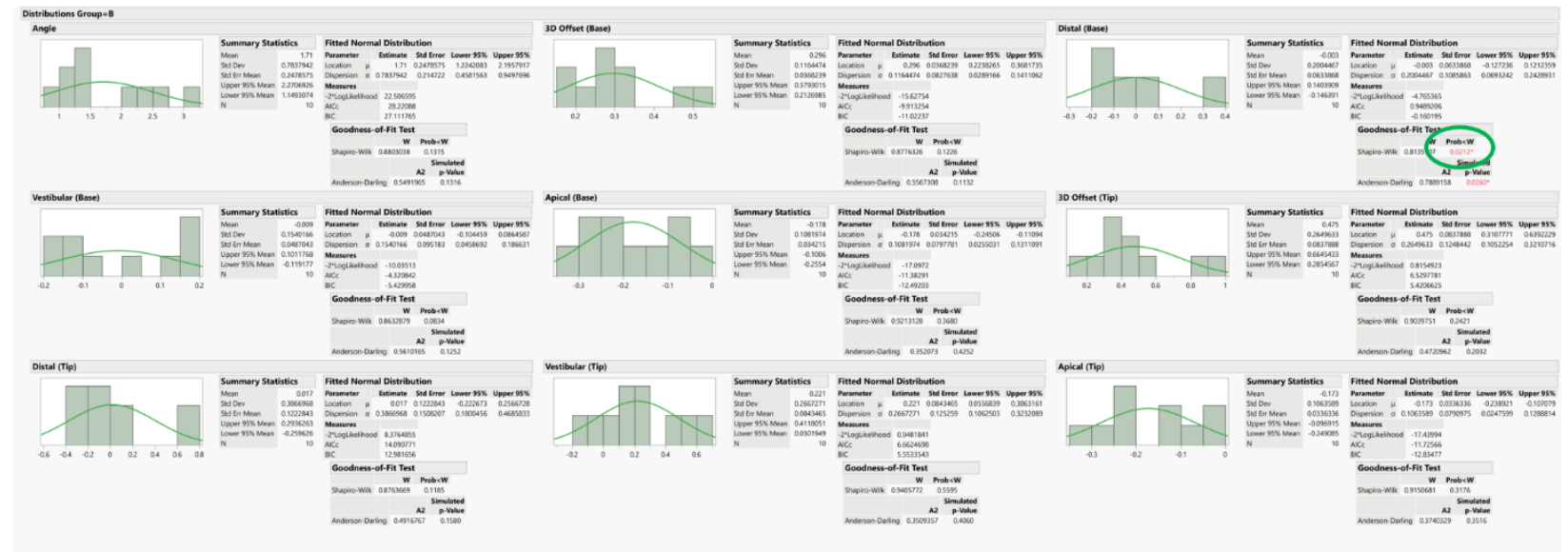

Figure A2 